This is the peer reviewed accepted manuscript of the following article:

Costa V, Carina V, Fontana S, De Luca A, Monteleone F, Pagani S, Sartori M, Setti S, Faldini C, Alessandro R, Fini M, Giavaresi G.

Osteogenic commitment and differentiation of human mesenchymal stem cells by low-intensity pulsed ultrasound stimulation.

J Cell Physiol. 2018 Feb;233(2):1558-1573.

Final peer reviewed version available at: https://doi.org/10.1002/jcp.26058

Rights / License:

The terms and conditions for the reuse of this version of the manuscript are specified in the publishing policy. For all terms of use and more information see the publisher's website.

This item was downloaded from IRIS Università di Bologna (https://cris.unibo.it/)

When citing, please refer to the published version. 


\section{OSTEOGENIC COMMITMENT AND DIFFERENTIATION OF HUMAN MESENCHYMAL STEM CELLS BY LOW-INTENSITY PULSED ULTRASOUND STIMULATION $^{\dagger}$}

Running head: Osteogenic Commitment \& Ultrasound Stimulation Viviana Costa $^{1{ }^{*}}$, Valeria Carina ${ }^{1 \uparrow,}$, Simona Fontana ${ }^{2}$, Angela De Luca ${ }^{1}$, Francesca Monteleone $^{2}$, Stefania Pagani ${ }^{3}$, Maria Sartori ${ }^{4}$, Stefania Setti ${ }^{5}$, Cesare Faldini', Riccardo Alessandro ${ }^{2}$, Milena Fini ${ }^{3,4}$, Gianluca Giavaresi ${ }^{1,3}$

1 Rizzoli Orthopedic Institute, Innovative Technological Platforms for Tissue Engineering, Theranostic and Oncology, Palermo, Italy;

2 Biology and Genetics Unit, Department of Biopathology and Medical Biotechnologies, University of Palermo, Italy;

3 Rizzoli Orthopedic Institute, Laboratory of Preclinical and Surgical Studies, Bologna, Italy;

4 Rizzoli Orthopedic Institute, Laboratory BITTA, Bologna, Italy;

5 IGEA SpA, Carpi (Modena), Italy;

6 Rizzoli Orthopedic Institute, $2^{\text {nd }}$ Orthopaedic and Traumatologic Clinic, Bologna, Italy.

"These authors contributed equally to this work.

* Corresponding Author:

Viviana Costa, Ph.D.

Rizzoli Orthopedic Institute

Via Divisi 83

90133, Palermo (ITALY)

Tel +390916554630

E-mail: viviana.costa@ior.it 


\begin{abstract}
Low-intensity pulsed ultrasound (LIPUS) as an adjuvant therapy in in vitro and in vivo bone engineering has proven to be extremely useful. The present study aimed at investigating the effect of $30 \mathrm{~mW} / \mathrm{cm}^{2}$ LIPUS stimulation on commercially available human mesenchymal stem cells (hMSCs) cultured in basal or osteogenic medium at different experimental time points $(7 \mathrm{~d}, 14 \mathrm{~d}, 21 \mathrm{~d})$. The hypothesis was that LIPUS would improve the osteogenic differentiation of hMSC and guarantying the maintenance of osteogenic committed fraction, as demonstrated by cell vitality and proteomic analysis. LIPUS stimulation (a) regulated the balance between osteoblast commitment and differentiation by specific networks (activations of RhoA/ROCK signaling and upregulation of Ribosome constituent/Protein metabolic process, Glycolysis/Gluconeogenesis, RNA metabolic process/Splicing and Tubulins); (b) allowed the maintenance of a few percentage of osteoblast precursors (21d CD73+/CD90+: 6\%; OCT-3/4+/NANOG+/SOX2+: 10\%); (c) induced the activation of osteogenic specific pathways shown by gene expression (early: $A L P L, C O L 1 A 1$, late: RUNX2, BGLAP, $M A P K 1 / 6)$ and related protein release (COL1a1, OPN, OC), in particular in the presence of osteogenic soluble factors able to mimic bone microenvironment. To summarize, LIPUS might be able to improve the osteogenic commitment of hMSCs in vitro, and, at the same time, enhance their osteogenic differentiation. This article is protected by copyright. All rights reserved
\end{abstract}

Key words: mesenchymal stem cells, low-intensity pulsed ultrasound, osteogenic commitment, osteoblast differentiation, proteomic analysis 


\section{Introduction}

Mesenchymal Stem Cells (MSCs) are multipotent adult stem cells commonly used for tissue engineering applications, which have been demonstrated to differentiate into osteoblasts, adipocytes or chondrocytes depending on the culture condition (Alvarez et al., 2015; McNamara et al., 2010). MSCs are characterized by self-renewal capability, the process by which stem cells proliferate and create further stem cells, maintaining their undifferentiated and multipotent state (Kuhn and Tuan, 2010; Pittenger et al., 1999).

The way stem cells participate in tissue generation, maintenance and repair, saving themselves from depletion and protecting the host from over-exuberant stem-cell proliferation, is regulated by a specific anatomic entity defined by Schofield in 1978 and described by Scadden in 2006 as stem-cell niche (Scadden, 2006; Schofield, 1978). Stem-cells receive specific signals from physical and biochemical clues of this niche environment by direct contact with basal membrane proteins and by binding with soluble mediators like growth factors and cytokines, or insoluble extracellular matrix proteins, acting like paracrine regulators of stem-cell function (Griffin et al., 2015).

Alternatively, adult stem or progenitor cells, such as MSCs, represent a promising resource for new bone formation via cell-based tissue engineering. These cells can be isolated from various adult tissues and are able to promote tissue repair through trophic effects on other cell types and immune-regulatory activities (Griffin et al., 2015). Until now, tissue engineering approaches were characterized by the use of hMSCs isolated by different tissues, alone or in combination with a biomimetic scaffold and/or a physical approach (such as ultrasound, pulsed electromagnetic fields or others), in order to accelerate bone restoration (Baker et al., 2015).

Therefore, it is fundamental to understand how to control and guide the fate of stem cells in culture by providing external stimuli, i.e. using specific surface topography and chemistry with the help of biomimetic biomaterials, or delivering chemical and genetic clues in the form of growth factors and cytokines (Griffin et al., 2015; Papadimitropoulos et al., 2014). The loss of MSC properties in vitro, probably due to the absence of the niche environment, might limit the utility of MSCs in cell-based regenerative medicine (Wang et al., 2014b). To avoid this phenomenon, three-dimensional environments (i.e. bioreactors) have been proposed to expand MSC, but these approaches require an initial phase of MSC growth on plastic, which is inevitably associated with the selection of adherent cellular fractions, already depleted of their earlier progenitors properties (Di Maggio et al., 2012). 
Recently, it has been showed that low intensity pulsed ultrasound (LIPUS) is able to positively influence the maintenance of MSC stemness (Kusuyama et al., 2015). LIPUS stimulation at $30 \mathrm{~mW} / \mathrm{cm}^{2}$ is an established, widely used and FDA-approved therapeutic treatment for accelerating bone healing in fractures and in delayed or established non-unions (Angle et al., 2011; Augat et al., 2005; El-Mowafi and Mohsen, 2005). LIPUS is a form of mechanical energy that is transmitted through and into living tissues as an acoustic pressure wave with compressions. It is able to induce micromotion on the extra cellular matrix (ECM), produce stable cell cavitation and increase cell permeability with pathways activation (mechanotransduction) (Azuma et al., 2001; Claes and Willie, 2007; Rawool et al., 2003). These changes lead to downstream alterations in gene expression, resulting in an acceleration of bone repair by up-regulating bone specific genes and signaling pathways such as the mitogen-activated protein kinase (MAPK) cascade (Angle et al., 2011; Appleford et al., 2007; Claes and Willie, 2007; Fung et al., 2014; Hu et al., 2014; Uddin and Qin, 2013). Additional reports suggest that ultrasound alters cellular membrane properties (cellular adhesion, membrane permeability, calcium flux, and proliferation), activating signal-transduction pathways that lead to proteomes regulation (Fischell et al., 1991; Maxwell et al., 1994). Importantly, exposure to ultrasound caused an increase in intracellular calcium in many cells types, such as fibroblast, monocyte and mesenchymal stem cells, suggesting that the mechanical effects disrupt the normal function of the membrane, permitting leaking of calcium into the cell. Cells employ calcium as a cofactor in regulating the activity of enzymes, many of which are associated with signal-transduction pathways and relative proteomes modulation (Johns, 2002). Regarding these aspects, through mass spectrometry (MS) based proteomic methods, it was attempted to define the expression profiling of membrane proteins in MSCs undergoing osteoblast differentiation, illustrating the effects of many growth factors on this process (Foster et al., 2005; Kratchmarova et al., 2005; Salasznyk et al., 2005). A comparison of the protein expression profiles in undifferentiated and fully differentiated hMSC might reveal expressional differences that provide important clues into the mechanism underlying the process from stem cells to osteoblasts.

The overall purpose of this study was to verify whether LIPUS stimulation was able to allow the osteoblast lineage commitment of hMSCs and differentiation. To this end, LIPUS with spatially averaged and temporally averaged (SATA) intensity of $30 \mathrm{~mW} / \mathrm{cm}^{2}$ was applied to hMSCs cultured in basal or osteogenic medium at different experimental time points. The MSC differentiation response to short- and long-term LIPUS stimulation was analyzed in terms of (a) changes in the expression of protein markers, through MS-based quantitative 
proteomic technologies, in order to identify protein networks; and (b) the modulation of different stem cell markers (CD73, CD90, CD105, OCT-3/4, NANOG, SOX2) and osteogenic pathways; both activated by LIPUS (Kuhn and Tuan, 2010; Liu and Lee, 2014; Pricola et al., 2009; Scherzed et al., 2016; Yoon et al., 2014).

\section{Material and Methods}

\section{Cell culture}

Commercially available Human Mesenchymal Stem Cells (hMSC, Lonza, Walkersville, MD USA) were cultured in Mesenchymal Stem Cell Growth Medium (MSCGM ${ }^{\mathrm{TM}}$ Bullet Kit, Lonza, Walkersville, MD USA) to expand them without inducing differentiation. The culture medium was changed every 3 days, and cells were split at $80-90 \%$ of confluence using StemPro Accutase (Gibco by Life Technologies, Grand Islands, NY USA). hMSCs were used at an early passage (P5) for all experiments. To obtain osteogenic differentiation, hMSCs were treated with hMSC Mesenchymal Stem Cell Osteogenic Differentiation Medium (OM) (hMSC Osteogenic Differentiation BulletKit ${ }^{\mathrm{TM}}$, Lonza, Walkersville, MD USA).

\section{LIPUS treatment}

The LIPUS exposure device, manufactured by IGEA SpA (Carpi-Modena, Italy), consists of an array of 5 transducers $(\varnothing 25 \mathrm{~mm})$, which are specifically designed for stimulating cell cultures in a 48-well plate (Fig.1). The LIPUS signal consisted of $200 \mu \mathrm{s}$ burst of $1.5 \mathrm{MHz}$ sine waves repeating at $1 \mathrm{kHz}$ and delivering $30 \mathrm{~mW} / \mathrm{cm}^{2}$ SATA intensity.

Twenty-four hours before LIPUS treatment, hMSC cells were seeded in 48-well plates (diameter $=11.0 \mathrm{~mm}$, surface area $=95 \mathrm{~mm}^{2}$, and thickness of the well bottom $\left.=1.2 \mathrm{~mm}\right)$ at different concentrations according to the different time points: 24 hours: 10000 cells/well; 7 days: 8000 cells/well; 14 days: 4000 cells/well; and 21 days: 2000 cells/well. For each experimental time point, hMSC cultures were divided in 4 groups: (a) Untreated MSCGM group (Control): cells were cultured in MSCGM and not exposed to LIPUS treatment; (b) LIPUS MSCGM group: cells were cultured in MSCGM and treated with LIPUS; (c) Untreated OM group: cells were cultured in OM and not exposed to LIPUS treatment; (d) LIPUS OM group: cells were cultured in OM and treated with LIPUS. Culture plates were then placed on the ultrasound transducer array with a thin layer of standard ultrasound gel and exposed to LIPUS for $20 \mathrm{~min} /$ day for 5 consecutive days/ week. The untreated groups were handled in the same way, but the ultrasound generator was switched off. At the end of LIPUS 
stimulation time, a culture plate for each group was cultured for further 7 days at the same condition in the incubator but without LIPUS exposure (indicated as 'off').

\section{hMSC viability (WST-1 test)}

WST-1 colorimetric reagent (Roche Diagnostics GmbH, Manheim, Germany) was used to evaluate cell viability. Briefly, WST-1 reagent (10\% vol/vol) was added to the cell monolayer in each well. After 4 hours of incubation, the formazan dye produced by viable cells was quantified spectrophotometrically at $450 \mathrm{~nm}$ by Bio-Rad Microplate Reader (Bio-Rad Laboratories, Hercules, CA, USA) and results were reported as percentage of viable cells compared to Untreated MSCGM group.

\section{DNA concentration (PicoGreen assay)}

DNA content was quantified by fluorometry using a Quant-iT PicoGreen dsDNA Assay Kit (Invitrogen $^{\mathrm{TM}}$, Life Technologies - EuroClone S.p.A, Pero-Milan, Italy). After sample washing with PBS, $100 \mu \mathrm{L}$ of lyis solution was added to each well and cell lysis was then completed by 3 freezes-thaw cycles at $-80^{\circ} \mathrm{C}$. DNA content was calculated from the lysates by adding $100 \mu \mathrm{L}$ of fluorescent nucleic acid stain to each sample. Fluorescence was measured using a GloMax multiwell plate reader (GloMax, Promega Corporation Madison, WI, USA).

\section{hMSC characterization}

To demonstrate hMSC phenotype maintenance, CD73, CD90 and CD105 antigen expressions were assessed using a Human MSC Analysis Kit (BD Bioscience 562245), whereas to analyze the stem cell transcriptional factor expression a Human Pluripotent Stem Cell Transcription Factor Analysis Kit (BD Bioscience 560589) was used. Briefly, a suspension of $1 \times 10^{6}$ cells was washed in PBS and re-suspended in flow cytometry buffer (FCB: $2 \%$ BSA in PBS) containing $0.5 \mu \mathrm{g} / \mathrm{ml}$ of conjugated antibody directed against CD73, CD90 and CD105, or specific conjugated IgG as isotype control. For the stem cell transcription factors analysis, a manufacturing protocol was followed. Cell fluorescence was evaluated by FlowSight (Amnis Corporation, Merck Millipore, USA) and data were analyzed using a Quantitative Imaging software (Amnis Corporation, Merck Millipore, USA).

Mineralization of differentiating hMSC cultures was assessed by the OsteoImage ${ }^{\mathrm{TM}}$ Mineralization Assaykit (Lonza) based on fluorescent staining of hydroxyapatite deposited by cells in bone-like nodules, which was then measured by a Glomax multiwall plate reader at 492/520nm excitation/emission. 
Reverse Transcriptase - quantitative Polymerase Chain Reaction (RT-qPCR) Analysis

Total RNA was extracted using a PureLink ${ }^{\mathrm{TM}}$ RNA Micro Kit (Invitrogen ${ }^{\mathrm{TM}}$ ) and reversetranscribed with a High Capacity cDNA Reverse Transcription Kit (Applied Biosystems ${ }^{\mathrm{TM}}$, Life Technologies - EuroClone S.p.A, Pero-Milan, Italy) following the manufacturer's instructions. Each cDNA sample was tested in duplicate.

qRT-PCR analysis was performed by Light Cycler 2.0 Instrument (Roche Diagnostics) using the SYBR ${ }^{\circledR}$ Green Real-Time PCR Master Mix (Applied Biosisystems ${ }^{\mathrm{TM}}$ ), QuantiTect Primers (Qiagen Srl, Milan, Italy) and custom made primers (Invitrogen ${ }^{\mathrm{TM}}$ ) (see Tables 1 and 2 ). The mean threshold cycle was used for the calculation of relative expression using the $2^{-}$ ${ }^{\Delta \Delta \mathrm{Ct}}$ method, against GAPDH as housekeeping gene (Livak and Schmittgen, 2001). Results were expressed as relative fold changes calculated using untreated MSCGM samples as calibrators for each experimental time point.

\section{ELISA assays}

Protein release in the culture medium was measured for alkaline phosphatase (ALP kit SEB472Hu), collagen type I alpha 1 (COL1a1 kit - SEA350Hu), osteopontin (OPN kit SEA899Hu) together with the cellular content of osteocalcin (OC kit - SEA471Hu) using a Cloud-Clone Corp ELISA KIT assay (Cloud-Clone Corp. Houston, TX, USA), according to the manufacturer's instructions. The values obtained were normalized to medium protein content evaluated by Bradford assay.

\section{Proteomic analyses}

Protein extraction and digestion

All chemicals used for protein extraction and digestion were of analytical grade, and Milli-Q water was employed in all buffers and solutions. At 14 days (Carina V et al. 2017 accepted), the cells of all groups were dissolved in $100 \mu \mathrm{L}$ of $50 \%$ tetrafluoroethylene (Sigma-Aldrich) in PBS, vigorously vortexed and sonicated for $7 \mathrm{~min}$ in an ice bath and finally incubated with constant shaking for $2 \mathrm{~h}$ at $60{ }^{\circ} \mathrm{C}$. Proteins were reduced with $5 \mathrm{mM}$ dithiothreitol (Sigma Aldrich SRL, Milan, Italy) for $30 \mathrm{~min}$ at $60{ }^{\circ} \mathrm{C}$ and alkylated with $25 \mathrm{mM}$ iodoacetamide (Sigma-Aldrich) for $30 \mathrm{~min}$ in the dark at room temperature. Before adding mass spectrometry-grade trypsin (Pierce ${ }^{\mathrm{TM}}$ Trypsin Protease, Fisher Scientific Italia, Rodano-Milan, Italy), the samples were diluted 5-fold with $100 \mathrm{mM}$ ammonium bicarbonate $\mathrm{pH}$ 8.0. Protein samples were digested by adding trypsin at a ratio of $1: 50(\mathrm{w} / \mathrm{w})$ for $18 \mathrm{~h}$ at $37{ }^{\circ} \mathrm{C}$ with constant shaking, in presence of $2 \mathrm{mM} \mathrm{CaCl}_{2}$. To stop digestion $50 \mu \mathrm{L}$ of $2.5 \%$ trifluoroacetic 
acid (TFA HPLC Grade, Sigma-Aldrich) were added to the samples. Digested samples were then centrifuged at $14,000 \mathrm{~g}$ for $10 \mathrm{~min}$ at $4{ }^{\circ} \mathrm{C}$. The resulting supernatant, containing the peptide mixture, was extracted using the $100 \mu \mathrm{L}$ Bond Elute OMIX C18 pipette tips (Agilent Technologies Italia SpA, Cernusco sul Naviglio - Milan, Italy). Eluted peptide mixtures were vacuum dried and reconstituted in 5\% acetonitrile $0.1 \%$ formic acid for mass spectrometry analyses. Duplicates of each sample were used for the following proteomic analysis.

Generation of the reference spectral library

Approximately $2 \mu \mathrm{g}$ of trptic peptides of each sample were run for Data-Dependent Acquisition (DDA) analysis. The resulting list of protein/peptides was used for construction of the Sequential Window Acquisition of all THeoretical (SWATH) reference spectral library. The sample was analyzed via reverse-phase high-pressure liquid chromatography electrospray ionization tandem mass spectrometry (RP-HPLC-ESI-MS/MS) using a TripleTOF® 5600 mass spectrometer (AB SCIEX, Milan, Italy). The mass spectrometer was coupled to a nanoLC Eksigent 425 system (AB SCIEX). RP-HPLC was performed with a trap and elution configuration using an Acclaim ${ }^{\mathrm{TM}}$ PepMap $^{\mathrm{TM}} 100$ Nano Trap Column $100 \mu \mathrm{m}$ x $2 \mathrm{~cm}, \mathrm{C} 18,5$ $\mu \mathrm{m}, 100 \AA$ (Fisher Scientific Italia) and an Acclaim ${ }^{\mathrm{TM}}$ PepMap $^{\mathrm{TM}}$ RSLC Nano Column $75 \mu \mathrm{m}$ x 250 mm, C18, $2 \mu \mathrm{m}, 100 \AA$ (Fisher Scientific Italia). The reverse-phase LC solvents were: solvent A $(0.1 \%$ formic acid in water) and solvent B (2\% water and $0.1 \%$ formic acid in acetonitrile). The sample was loaded in the trap column at a flow rate of $5 \mu \mathrm{L} / \mathrm{min}$ for $10 \mathrm{~min}$ using a solvent, from loading pump, containing $2 \%$ acetonitrile and $0.1 \% \mathrm{v} / \mathrm{v}$ TFA in water and eluted at a flow rate of $300 \mathrm{~nL} / \mathrm{min}$ using a gradient method according to which solvent $\mathrm{B}$ is linearly increased from $2 \%$ to $10 \%$ within $10 \mathrm{~min}$, from $10 \%$ to $30 \%$ within $110 \mathrm{~min}$ and then to $60 \%$ within $15 \mathrm{~min}$; afterwards, phase $\mathrm{B}$ is further increased to $95 \%$ within $2 \mathrm{~min}$. Phase B is maintained at $95 \%$ for 10 min to rinse the column. Finally, B is lowered to $2 \%$ over $2 \mathrm{~min}$ and the column re-equilibrated for $21 \mathrm{~min}$ (170 min total run time). The eluting peptides were on-line sprayed in the Triple TOF 5600 Plus mass spectrometer, that it is controlled by Analyst TF 1.7 software (AB SCIEX).

Each of the four samples used to generate the SWATH-MS spectral library was subjected to two DDA runs. For these eight experiments, the mass range for MS scan was set to $\mathrm{m} / \mathrm{z} 400$ 1250 and the MS/MS scan mass range was set to $\mathrm{m} / \mathrm{z} 230-1,500$. Using the mass spectrometer, a 0.25 s survey scan (MS) was performed, and the top 50 ions were selected for subsequent MS/MS experiments employing an accumulation time of $0.065 \mathrm{~s}$ per MS/MS experiment for a total cycle time of 3.5485 s. Precursor ions were selected in high resolution 
mode $(>30,000)$, tandem mass spectra were recorded in high sensitivity mode (resolution $>15,000)$. The selection criteria for parent ions included an intensity of greater than $500 \mathrm{cps}$ and a charge state ranging from +2 to +5 . A $15 \mathrm{~s}$ dynamic exclusion was used. The ions were fragmented in the collision cell using rolling collision energy, and a collision energy spread (CES) of $5 \mathrm{~V}$.

Eight DDA MS raw files were combined and subjected to database searches in unison using ProteinPilot ${ }^{\mathrm{TM}} 4.5$ software (ASCIEX) with the Paragon algorithm by using the following parameters: iodoacetamide cysteine alkylation, digestion by trypsin and no special factors. The search was conducted through identification efforts in a UniProt Swiss-Prot database (http://www.uniprot.org/, downloaded in July 2014, with 137216 protein sequence entries) containing whole Homo sapiens proteins. A false discovery rate analysis was also performed.

SWATH-MS analysis and targeted data extraction

Two replicates of each sample were subjected to the cyclic data independent acquisition (DIA) of mass spectra. Data were acquired by repeatedly cycling through 40 consecutive 15Da precursor isolation windows (swaths). For these experiments, the mass spectrometer was operated using a $0.1 \mathrm{~s}$ survey scan (MS). The subsequent MS/MS experiments were performed across the mass range of 100 to $1600 \mathrm{~m} / \mathrm{z}$ on all precursors in a cyclic manner using an accumulation time of $0.03 \mathrm{~s}$ per SWATH window for a total cycle time of $1.3490 \mathrm{~s}$. Ions were fragmented for each MS/MS experiment in the collision cell using rolling collision energy, and CES was set to 15 . The spectral alignment and targeted data extraction of DIA samples were performed using PeakView v.2.2 (AB SCIEX) with the reference spectral library. All eight DIA files were loaded and exported in .txt format in unison using an extraction window of $15 \mathrm{~min}$ and the following parameters: three hundred peptides/protein, seven transitions/peptide, peptide confidence level of $90 \%$, excluded shared and modifies peptides, and an extracting ion current (XIC) width of $75 \mathrm{ppm}$. This export procedure generated three distinct files containing the quantitative output for (1) the peak area under the intensity curve for individual ions, (2) the summed intensity of individual ions for a given peptide, and (3) the summed intensity of peptides for a given protein. For each protein, seven individual ion intensities were summed as peptide intensity, until three hundred peptides intensities were summed as protein intensity. The protein list with False Discovery Rate (FDR) lower than 5\% generated by analyzing SWATH data with PeakView 2.2, was exported to MarkerView 1.2.1 (AB SCIEX) for statistical analysis. 


\section{Statistical analysis}

Statistical analysis was performed using the IBM SPSS Statistics 23 software. Data are reported as mean \pm standard deviation (SD) with of $p<0.05$ considered significant. The Kolmogorov-Smirnov test was performed to test variables normality. The General Linear Model (GLM) with adjusted Sidak's multiple comparison test with 'group' (Untreated OM, LIPUS MSCGM and LIPUS OM) and 'experimental time' (24h, 7d, 14, 14d on $+7 \mathrm{~d}$ off, 21d and $21 \mathrm{~d}$ on $+7 \mathrm{~d}$ off) as fixed effects, was performed to assess the influence of LIPUS treatment on hMSCs osteogenic differentiation. Precision of the reported coefficients was assessed by creating 1,000 bootstrap samples from the entire data set and repeating the estimation process. Standard errors of the means and significances were obtained using this bootstrap method of the corresponding sampling distributions. In particular, the following comparisons were taken into account:

- within each 'experimental time': LIPUS OM versus Untreated OM and LIPUS MSCGM;

- within each 'group': $14 \mathrm{~d}$ versus $7 \mathrm{~d} ; 21 \mathrm{~d}$ versus $14 \mathrm{~d} ; 14 \mathrm{~d}$ on $+7 \mathrm{~d}$ off versus $14 \mathrm{~d} ; 21 \mathrm{~d}$ on $+7 \mathrm{~d}$ off versus $21 \mathrm{~d}$; $14 \mathrm{~d}$ on $+7 \mathrm{~d}$ off versus $21 \mathrm{~d}$; $21 \mathrm{~d}$ on $+7 \mathrm{~d}$ off versus $14 \mathrm{~d}$ on $+7 \mathrm{~d}$ off.

Regarding the analysis of protein list, a pairwise t-test and principal component analysis (PCA) were done by using MarkerView 1.2.1 software. Heat map clustering of all quantified proteins was performed by using Heatmapper free available web server (http://www.heatmapper.ca). Mean of replicates was used for performing the following paired comparison: (i) Untreated MSCGM versus Untreated OM; (ii) Untreated MSCGM versus LIPUS MSCGM; (iii) LIPUS MSCGM versus Untreated OM; (iv) LIPUS OM versus Untreated OM; (v) LIPUS MSCGM versus LIPUS OM of all different growth conditions. Fold Change (FC) thresholds at 1.5 with an adjusted $p$-value $<0.05$ were used to consider a protein up or down-regulated. The molecular interaction networks among the significantly modulated proteins was analyzed by STRING v10 (Search Tool for the Retrieval of Interacting Genes/Proteins; http://string-db.org/) using the confidence level $>0.7$. Of note, the reported networks not include all proteins significantly up- or down-modulated since disconnected nodes are hidden for visualizing molecular interactions. 


\section{Results}

\section{Proteomics Analysis}

To understand the proteomes patterns of hMSCs maintained in MSCGM and OM or after LIPUS treatments, a SWATH quantitation for all samples was performed. A list of 787 proteins was identified, as reported in Supplementary Table 1 online (sheet "Spectral reference library"). In addition, data were validated by using Peakview 2.2 software, obtaining a quantitative information for 555 proteins (Supplementary Table 1 online, sheet "Protein quantification"). Then, PCA and heat map clustering were carried out to acquire a comprehensive structure of the behavior of all quantified proteins under different growth conditions. PCA projection demonstrates that the maximum variability in the dataset, regardless of exposure to LIPUS, occurs between cells grown in presence of MSCGM or OM with the first component covering $68.1 \%$ of the data variance (Fig. 2a). This result is also reflected in the Heat Map, where two major clusters separating the protein abundance profile of hMSCs grown in presence of MSCGM (both Untreated and LIPUS) and OM (both Untreated and LIPUS) can be observed (Fig. 2b). The lists of proteins obtained for each paired comparison were found differentially expressed (Supplementary Table 1, sheet "Protein quantification").

The comparison "Untreated MSCGM versus Untreated OM" was considered as the "reference comparison" since cells in MSCGM maintained their sternness, while in OM were induced to osteogenic differentiation. Thus, the protein profile of LIPUS MSCGM cells was compared to which of cells grown in Untreated OM, as well as to Untreated MSCGM cells in order to better define the molecular strategies through which LIPUS specifically affects the hMSCs behavior. Venn diagrams reported in Figure 3 highlighted that about $38 \%$ of proteins modulated in the Untreated MSCGM versus LIPUS MSCGM comparison (13 up-regulated and 5 down-regulated out of 50 differentially expressed) showed the same trend in the reference comparison, indicating that compared to the basal condition (Untreated MSCGM) the addition of LIPUS induced effects comparable to osteogenic differentiation, as already reported in several published studies (Azuma et al., 2001; Rutten et al., 2009). In details, SWATH-MS analysis showed some significantly LIPUS-modulated proteins specifically related to osteogenic differentiation: (a) Cytoskeletal reorganization proteins that directly stimulates osteoblastic differentiation (CCT2, CALD1 and CTTN 9) (Higuchi et al., 2009); (b) Galectin 3, which is involved in osteogenesis and formation of bone nodules (LGALS3) (Aubin et al., 1996); 
(c)Profilin 1, which is down-regulated in osteogenic differentiation process (PFN1) (Lin et al., 2016); and (d) Osteonectin, a marker of osteogenic differentiation (SPARC) (Delany et al., 2003; Jundt et al., 1987;

Kessler and Delany, 2007) (Supplementary Table 2 and Figure S1).

In the LIPUS MSCGM versus Untreated OM comparison it was interesting to note that about $58 \%$ of modulated proteins (45 up-regulated and 30 down-regulated out of 128 differentially expressed) showed the same trend in the reference comparison. Moreover, STRING analysis of the modulated protein dataset, showing only high confidence functional connections (confidence score $\geq 0.7$ ), highlighted two interesting aspects.

The first one concerned the down regulation in LIPUS MSCMG cells, of proteins associated to Ras homolog gene family, member A (RhoA) protein and its activity as a positive regulator of hMSCs osteogenic differentiations (Fig. 4a) (Chen et al., 2011). In particular, it was found that the triple functional domain protein (Trio), a specific RhoA activator, was downregulated in undifferentiated hMCSs ( -14 fold $/ p=0.0106$ in Untreated MSCGM cells versus Untreated OM cells; Supplementary Table 1, sheet "Protein quantification"), as well as in presence of LIPUS ( -25.4 fold $/ p=0.0060$ in LIPUS MSCGM cells versus untreated OM cells; Supplementary Table 1, sheet "Protein quantification"). It was interesting to find that also in hMSCs grown in LIPUS OM there was a consistent down-regulation of TRIO in comparison to cells grown in Untreated OM ( -42.6 fold $/ p=0.0058$ in LIPUS OM cells versus untreated OM cells; Supplementary Table 1, sheet "Protein quantification").

The second aspect emerged from STRING analysis was that in comparison to OM stimulation, Untreated MSCGM cells (Fig. 4b) and LIPUS MSCGM cells (Fig. 4c) were characterized by the up-regulation of proteins forming four overlapping functional networks: Ribosome constituent/Protein metabolic process (green area: 36 proteins in Untreated MSGCMG cells and 27 in LIPUS MSGCMG cells), Glycolysis/Gluconeogenesis (blue area: 4 proteins in both cells), RNA metabolic process/Splicing (pink area: 9 proteins in Untreated MSGCMG cells and 3 in LIPUS MSGCMG cells), tubulins (yellow area: 3 proteins in Untreated MSGCMG cells and 2 in LIPUS MSGCMG cells).

\section{Cell viability and dsDNA content}

Cell viability was higher in all groups in comparison with Untreated MSCGM at 7, 14 and 21 days (Fig. 5a), followed by a constant decrease. A progressive increase in dsDNA content within 21 days was observed in Untreated OM (Fig. 5b), even though dsDNA content values were lower than those in Untreated MSCGM (except at 21days). When LIPUS stimulation was applied, an increase in dsDNA content was observed compared to Untreated MSCGM, 
where dsDNA remained constant even after LIPUS stimulus was stopped. The simultaneous presence of OM medium and LIPUS stimulation (LIPUS OM) determined significant changes in hMSC dsDNA content compared to Untreated OM (21d: $-73 \%, p<0.0005 ; 14 \mathrm{~d}$ 'on' $+7 \mathrm{~d}$ 'off': $139 \%, p<0.0005)$ and LIPUS MSCGM (7d: $-32 \%, p<0.05 ; 14 \mathrm{~d}: d=-33 \%, p<0.005$; 21d: $d=-68 \%, p<0.0005)$.

\section{hMSC characterization}

Flow cytometry results showed that hMSCs were positive for the MSC markers CD73 (40 54\%), CD90 (27 - 48\%) and CD105 (31-84\%), and for the stem cell transcriptional factors NANOG (10-34\%), SOX2 (10-34\%) and OCT-3/4 (28 - 61\%) at 21 days. Figure 6 (a-d) shows a percentage of hMSC positive gates for CD73, CD90 and CD105 at 21 days. The double positive hMSC populations co-expressing stem cell markers showed a similar decreasing trend over time and among cultures, whereas those co-expressing stem cell transcriptional factors showed an increasing trend with the highest values in LIPUS-treated cultures (Fig. 6e).

OsteoImage ${ }^{\mathrm{TM}}$ Mineralization assay showed that hMSCs maintained in OM had more calcium nodule formation than those cultured in MSCGM medium (Fig. 7). In all groups, significant increases in mineralization were observed over time. The LIPUS OM group presented the highest hydroxyapatite content compared to Untreated OM (7d: 39\%; 14d: 20\%; 21d: 7\%) and LIPUS MSCGM (7d: 30\%; 14d: 64\%; 21d: 37\%) groups at each experimental time.

\section{$R T-q P C R$ analysis}

LIPUS stimulation induced an increase in gene expression of RUNX2, ALPL, COL1A1 and BGLAP compared to Untreated MSCGM at 7 (COL1A1 and BGLAP) and 21 days (RUNX2, $A L P L$ and COL1A1) (Fig. 8). In Untreated OM and LIPUS OM a lower expression of RUNX2 compared to Untreated MSCGM was found, which increased after the cessation of LIPUS stimulation and/or differentiating medium (Fig. 8a). A significantly lower value in the expression of RUNX2 at 21days was observed between LIPUS OM and LIPUS MSCGM. The combination of LIPUS stimulation with OM (LIPUS OM) led to an increase in ALPL expression compared to Untreated OM $(40 \%, p<0.05)$ and LIPUS MSCGM $(97 \%, p<0.05)$ (Fig. 8b). Changes in the expression of $A L P L$ observed over time showed a maximum increase in expression at 21 days with a significant decrease 7 days after the cessation of any stimuli $(p<0.005)$. The expression of COL1A1 was greater in LIPUS MSCGM than in LIPUS OM $(68 \%, p<0.05)$ and it was lower in LIPUS OM and Untreated OM compared to 
the Untreated MSCGM group, except for the expression at 21 days (Fig. 8c). SPP1 presented the highest expression at 7 days (46 -fold increase), decreasing after 14 days of culture with values lower than the control group (Untreated MSCGM) (Fig. 8d). Similarly, BGLAP expression levels (Fig. 8e) decreased significantly from 7 to 14 days, but in LIPUS OM the decrease did not occur until the cessation of LIPUS and OM stimuli, but remained constant at 7,14 and 21 days.

LIPUS treatment and OM medium induced an up-regulation overtime of MAPK1 in all groups in comparison with Untreated MSCGM, reaching its highest values 7 days after the cessation of stimuli administered up to day 21 (Fig. 9a). In particular, the highest MAPK1 expression was found in Untreated OM at 21 days 'on' +7 days 'off' $(p<0.0005)$ compared to LIPUS OM. Conversely, both stimuli determined a down-regulation of MAPK6 in Untreated OM and LIPUS MSCGM, which resolved after the cessation of stimuli (Fig. 9b). The MAPK6 expression in LIPUS OM group showed a different trend with a progressive up-regulation, reaching the highest value at 14 days compared to LIPUS MSCGM $(p<0.05)$, followed by a down-regulation overtime.

\section{ELISA assays}

ELISA results are reported in Figure 10. No significant increases in the production of ALP were observed in any of the groups other than Untreated MSCGM. In Untreated OM, COL1a1 synthesis was increased by about 2.4\%, compared to Untreated MSCGM, whereas LIPUS stimulation increased COL1a1 synthesis by $0.5 \%$ (LIPUS MSCGM). COL1a1 release increased by $2.6 \%$ in LIPUS OM compared to Untreated MSCGM; this was very different from LIPUS MSCGM $(369 \%, p<0.005)$. In all groups, high and modest increases in OC and OPN release, respectively, were observed. OC synthesis results indicated that OM medium (Untreated OM) or LIPUS treatment (LIPUS MSCGM and LIPUS OM) produced on average a similar OC increase by approximately 30\% compared to Untreated MSCGM. Conversely, in Untreated OM or LIPUS MSCGM, OPN release was 2\% compared to Untreated MSCGM, whereas the combined OM and LIPUS stimuli (LIPUS OM) determined only a $0.5 \%$ increase, which was significantly lower by about 70\% $(p<0.05)$ compared to the Untreated OM and LIPUS MSCGM groups. 


\section{Discussion}

Different studies have been performed on the effects of LIPUS on cells attempting to describe the cellular response to biomechanical stimuli (Frairia and Berta, 2011) or transient membrane permeability (Engler et al., 2006; Huang et al., 2013; McBeath et al., 2004). In the present study, the role of LIPUS stimulation (SATA intensity at $30 \mathrm{~mW} / \mathrm{cm}^{2}$ ) in $\mathrm{hMSC}$ osteogenic commitment and differentiation was investigated using an in vitro model, where LIPUS stimulation was evaluated in terms of proteome, gene expression, and proteins release modulation.

PCA and heat map clustering analyses of the obtained proteomic data, suggested that the most significant differences in protein expression profiles of MSCs are due to the specific growth medium (MSCGM or OM) rather than the exposure to LIPUS. Very few studies were focused indeed on osteogenic differentiation of hMSC (Gao et al., 2016; Hu et al., 2014; Yue et al., 2013) mediated by LIPUS treatment. In this sense, our proteomics analysis revealed the existence of differences in osteoblast commitment and differentiation potential between all experimental groups. Thus, deeper proteomic data analysis showed the peculiar ability of LIPUS to positively regulate several proteins and pathways associated with stemness, such as the autophagosomes proteins SQSTM1, SRSF2, TMEM109 or Glycolysis/Gluconeogenesis proteins (CKAP4,COX4I, ALDOA) (Folmes et al., 2011; Folmes and Terzic, 2016), and to negatively regulate signaling networks associated to the differentiation of MSCs into osteoblasts, such the RhoA/ROCK pathway (Chen et al., 2011; Fang et al., 2008; Yun et al., 2016). In particular, our quantitative proteomic analysis indicated that, regardless the grown medium, LIPUS exposure induced a consistent down-regulation of Trio, a specific RhoA activator. The Rho family of small GTPases controls a diverse array of cellular processes, including cytoskeletal dynamics, cell polarity, membrane transport, and gene expression. The RhoA is a molecular switch that respond to cell surface receptors for various cytokines, growth factors, adhesion molecules, and G-protein-coupled receptors by cycling between an inactive guanosine diphosphate (GDP)-bound and an active guanosine triphosphate (GTP)bound form. Recently Chen et al. demonstrated that during the differentiation process in bone marrow stem cell lines, RhoA protein expression increases on the membrane in the activated form of GTP-binding protein activating cellular actin remodeling and cytoskeleton rearrangement (Chen et al., 2011).

Regarding hMSC viability and proliferation, LIPUS stimulation or the presence of OM determined an increase in cell viability over time. Even though dsDNA content levels did not 
reach those observed in Untreated MSCGM, LIPUS MSGCM cells showed higher dsDNA values than those treated with LIPUS stimulation and OM. In fact, the simultaneous presence of OM and LIPUS stimulation (LIPUS OM) inhibited cell proliferation, thus resulting in significantly lower dsDNA content at each experimental time point, which was likely due to the start of the differentiation process (Wang et al., 2014a).

The analysis of specific markers of hMSC, confirmed the proteomic data of Untreated MSGCM and LIPUS MSGCM. The phenotypic characterization permitted to identify a functional multipotent hMSC stemness potency maintenance (CD73+/CD90+/CD105+) in the tested groups until 14 days, which decreased at 21days concurrently with osteoblast differentiation (Kern and Shibata, 2007; Pittenger et al., 1999; Ringdén and Le Blanc, 2006; Rutten et al., 2009; Saalbach et al., 2000; Yoshimura et al., 2007; Yoshimura et al., 2006). In addition, LIPUS stimulation markedly promoted the expression of stem cell transcriptional factors OCT-3/4, SOX2 and NANOG related to stemness maintenance, as recently reported by Kusuyama et al. (Alvarez et al., 2015; Kusuyama et al., 2015). As for the tendency of MSCs to lose their multipotency over time in culture, flow cytometry data recorded at different experimental time points might be consistent with long term culture stress, as reported by Stolzing et al. (Stolzing et al., 2006). In particular, according to Hassters et al. the loss of CD73 in hMSCs culture might be due to either a down-regulation of CD73 or a beginning of differentiation with the formation of a subpopulation of cells not expressing CD73 (Haasters et al., 2009).

These data suggested that hMSCs treated with LIPUS might maintain the expression of mesenchymal markers and increase the hMSC osteoblast lineage commitment (Kulterer et al., 2007) and differentiation especially after LIPUS and OM stimulation.

Finally, an increase in mineralization in Untreated OM and, interestingly, in LIPUS OM occurred after only 7 days, thus confirming a prompt transition from a proliferative state (hMSCs) towards a differentiating state, mostly after LIPUS treatment (LIPUS OM showed the highest calcium nodule formation capability).

The current results suggested that in vitro LIPUS stimulation induced the activation of the osteogenic specific pathways and relative protein release (Claes and Willie, 2007), favoring bone formation, in particular in the presence of osteogenic soluble factors that mimic bone microenvironment. RUNX2 expression was analyzed because it is (a) a fundamental transcription factor for osteogenic differentiation (Ducy et al., 1997; Otto et al., 2003); and (b) the target of mechanical signals by which physical stimuli act on the metabolic activities of osteoblasts (Ziros et al., 2002). RUNX2 mRNA expression level was increased in comparison 
to Untreated MSCGM at experimental times next to 21 days. The analysis of gene targets of RUNX2 and their protein release showed that higher values of COL1A1 mRNA expression were found in LIPUS MSCGM compared to LIPUS OM, whereas COL1a1 protein release increased in LIPUS OM compared to LIPUS MSCGM. This is suggestive of an additive effect of LIPUS in osteoblast-specific protein release. SPPI mRNA analysis showed that hMSCs in LIPUS groups presented an instable expression over time, whereas OPN protein release slightly increased in LIPUS OM. Furthermore, BGLAP mRNA expression levels in LIPUS OM did not occur until the cessation of stimuli; whereas OC synthesis indicated that OM (Untreated OM) or LIPUS treatment (LIPUS MSCGM and LIPUS OM) produced a similar OC increase of Untreated MSCGM.

The combination of LIPUS stimulation with OM led to a statistically significant increase in ALPL mRNA expression at 21 days of treatment both in comparison to Untreated OM group and LIPUS MSGCM, indicating an additive effect of LIPUS on ALPL gene regulation. The release of ALP did not increase with the OM and/or LIPUS stimulation and the highest ALP release was observed in Untreated MSGCM. Most likely, Untreated MSGCM showed an increase in ALP release because there were more osteoblasts committed cells compared to other groups, as demonstrated by phenotypic characterization and gene expression analysis. In addition, ALP data suggested the presence of intracellular control to maintain the balance between mRNA transcription and transduction, in order to allow the synthesis of a correct quantity of specific osteoblast protein throughout the differentiation pathway.

As the effect of LIPUS on MAPK signaling is concerned, LIPUS stimulation and OM induced an up-regulation of MAPK1 mRNA expression in all groups over time, but both stimuli determined a down-regulation of MAPK6. MAPK6 expression in the LIPUS OM group showed a different trend with a progressive up-regulation, reaching its highest value at 14 days of culture compared to LIPUS MSCGM, followed by down-regulation over time. Therefore, an effect of LIPUS on MAPK1/6 up-regulation was detected at gene expression level only after the ultrasound stimulus was stopped. This is probably due to the fact that at 7 and 14 days MAPK1/6 synthesis could have been already stimulated by the previous exposition to LIPUS (Sato et al., 2015). At later time points, after the end of stimulation (7days off), gene up-regulation could be a direct consequence of ultrasounds-induced mechanotransduction, confirming the role of LIPUS as an activator of multiple mechanosensitive pathways.

To sum up, the current study suggests that LIPUS might be able to maintain, in vitro for a long time, the niche of osteoblast committed hMSCs. Indeed, all data indicated that 
compared to Untreated OM, LIPUS exposure down regulates some pathways associated to osteogenic differentiation and allowed cells to maintain a protein expression profile characterizing the MSCs, providing new indication on the specific role that LIPUS could have in supporting the osteoblast commitment and differentiation of hMSCs.

\section{ACKNOWLEDGEMENTS}
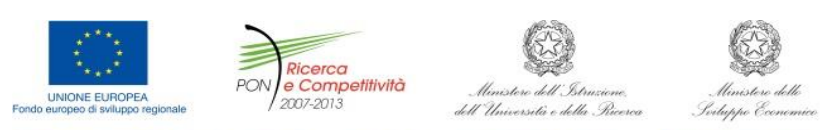

The study was developed with the contribution of the National Operational

investiamo nel vostrofuturo Programme for Research and

Competitiveness 2007-2013 - PON01_00829 “Piattaforme Tecnologiche per 1'Ingegneria Tissutale" and PON03_00011 "Potenziamento strutturale di una rete di eccellenza per la ricerca preclinica e clinica sulla terapia personalizzata in oncologia e in medicina rigenerativa". Operational Programme ERDF 2007-2013 in the region Emilia-Romagna: Activity 1.1 "Creation of technology centers for Industrial research and technological transfer"; and by Rizzoli Orthopedic Institute (“Cinque per mille 2012”). No benefits in any form were received or will be received from a commercial party related directly or indirectly to the subject of this article. 


\section{References}

Alvarez R, Lee HL, Wang CY, Hong C. 2015. Characterization of the osteogenic potential of mesenchymal stem cells from human periodontal ligament based on cell surface markers. Int J Oral Sci 7:213-219.

Angle SR, Sena K, Sumner DR, Virdi AS. 2011. Osteogenic differentiation of rat bone marrow stromal cells by various intensities of low-intensity pulsed ultrasound. Ultrasonics 51(3):281-288.

Appleford MR, Oh S, Cole JA, Protivínský J, Ong JL. 2007. Ultrasound effect on osteoblast precursor cells in trabecular calcium phosphate scaffolds. Biomaterials 28(32):47884794.

Aubin JE, Gupta AK, Bhargava U, Turksen K. 1996. Expression and regulation of galectin 3 in rat osteoblastic cells. J Cell Physiol 169(3):468-480.

Augat P, Simon U, Liedert A, Claes L. 2005. Mechanics and mechano-biology of fracture healing in normal and osteoporotic bone. Osteoporos Int 16 Suppl 2:S36-43.

Azuma Y, Ito M, Harada Y, Takagi H, Ohta T, Jingushi S. 2001. Low-intensity pulsed ultrasound accelerates rat femoral fracture healing by acting on the various cellular reactions in the fracture callus. J Bone Miner Res 16(4):671-680.

Baker N, Sohn J, Tuan RS. 2015. Promotion of human mesenchymal stem cell osteogenesis by PI3-kinase/Akt signaling, and the influence of caveolin-1/cholesterol homeostasis. Stem Cell Res Ther 6:238.

Chen Z, Wang X, Shao Y, Shi D, Chen T, Cui D, Jiang X. 2011. Synthetic osteogenic growth peptide promotes differentiation of human bone marrow mesenchymal stem cells to osteoblasts via RhoA/ROCK pathway. Mol Cell Biochem 358(1-2):221-227.

Claes L, Willie B. 2007. The enhancement of bone regeneration by ultrasound. Prog Biophys Mol Biol 93(1-3):384-398.

Delany AM, Kalajzic I, Bradshaw AD, Sage EH, Canalis E. 2003. Osteonectin-null mutation compromises osteoblast formation, maturation, and survival. Endocrinology 144(6):2588-2596.

Di Maggio N, Mehrkens A, Papadimitropoulos A, Schaeren S, Heberer M, Banfi A, Martin I. 2012. Fibroblast growth factor-2 maintains a niche-dependent population of selfrenewing highly potent non-adherent mesenchymal progenitors through FGFR2c. Stem Cells 30(7):1455-1464.

Ducy P, Zhang R, Geoffroy V, Ridall AL, Karsenty G. 1997. Osf2/Cbfa1: a transcriptional activator of osteoblast differentiation. Cell 89(5):747-754.

El-Mowafi H, Mohsen M. 2005. The effect of low-intensity pulsed ultrasound on callus maturation in tibial distraction osteogenesis. Int Orthop 29(2):121-124.

Engler AJ, Sen S, Sweeney HL, Discher DE. 2006. Matrix elasticity directs stem cell lineage specification. Cell 126(4):677-689.

Fang WB, Ireton RC, Zhuang G, Takahashi T, Reynolds A, Chen J. 2008. Overexpression of EPHA2 receptor destabilizes adherens junctions via a RhoA-dependent mechanism. J Cell Sci 121(Pt 3):358-368.

Fischell TA, Abbas MA, Grant GW, Siegel RJ. 1991. Ultrasonic energy. Effects on vascular function and integrity. Circulation 84(4):1783-1795.

Folmes CD, Nelson TJ, Martinez-Fernandez A, Arrell DK, Lindor JZ, Dzeja PP, Ikeda Y, Perez-Terzic C, Terzic A. 2011. Somatic oxidative bioenergetics transitions into pluripotency-dependent glycolysis to facilitate nuclear reprogramming. Cell Metab 14(2):264-271.

Folmes CD, Terzic A. 2016. Energy metabolism in the acquisition and maintenance of stemness. Semin Cell Dev Biol 52:68-75. 
Foster LJ, Zeemann PA, Li C, Mann M, Jensen ON, Kassem M. 2005. Differential expression profiling of membrane proteins by quantitative proteomics in a human mesenchymal stem cell line undergoing osteoblast differentiation. Stem Cells 23(9):1367-1377.

Frairia R, Berta L. 2011. Biological effects of extracorporeal shock waves on fibroblasts. A review. Muscles Ligaments Tendons J 1(4):138-147.

Fung CH, Cheung WH, Pounder NM, Harrison A, Leung KS. 2014. Osteocytes exposed to far field of therapeutic ultrasound promotes osteogenic cellular activities in preosteoblasts through soluble factors. Ultrasonics 54(5):1358-1365.

Gao Q, Walmsley AD, Cooper PR, Scheven BA. 2016. Ultrasound Stimulation of Different Dental Stem Cell Populations: Role of Mitogen-activated Protein Kinase Signaling. J Endod 42(3):425-431.

Griffin MF, Butler PE, Seifalian AM, Kalaskar DM. 2015. Control of stem cell fate by engineering their micro and nanoenvironment. World J Stem Cells 7(1):37-50.

Haasters F, Prall WC, Anz D, Bourquin C, Pautke C, Endres S, Mutschler W, Docheva D, Schieker M. 2009. Morphological and immunocytochemical characteristics indicate the yield of early progenitors and represent a quality control for human mesenchymal stem cell culturing. J Anat 214(5):759-767.

Higuchi C, Nakamura N, Yoshikawa H, Itoh K. 2009. Transient dynamic actin cytoskeletal change stimulates the osteoblastic differentiation. J Bone Miner Metab 27(2):158-167.

Hu B, Zhang Y, Zhou J, Li J, Deng F, Wang Z, Song J. 2014. Low-intensity pulsed ultrasound stimulation facilitates osteogenic differentiation of human periodontal ligament cells. PLoS One 9(4):e95168.

Huang C, Holfeld J, Schaden W, Orgill D, Ogawa R. 2013. Mechanotherapy: revisiting physical therapy and recruiting mechanobiology for a new era in medicine. Trends Mol Med 19(9):555-564.

Johns LD. 2002. Nonthermal effects of therapeutic ultrasound: the frequency resonance hypothesis. J Athl Train 37(3):293-299.

Jundt G, Berghäuser KH, Termine JD, Schulz A. 1987. Osteonectin--a differentiation marker of bone cells. Cell Tissue Res 248(2):409-415.

Kern SE, Shibata D. 2007. The fuzzy math of solid tumor stem cells: a perspective. Cancer Res 67(19):8985-8988.

Kessler CB, Delany AM. 2007. Increased Notch 1 expression and attenuated stimulatory G protein coupling to adenylyl cyclase in osteonectin-null osteoblasts. Endocrinology 148(4):1666-1674.

Kratchmarova I, Blagoev B, Haack-Sorensen M, Kassem M, Mann M. 2005. Mechanism of divergent growth factor effects in mesenchymal stem cell differentiation. Science 308(5727):1472-1477.

Kuhn NZ, Tuan RS. 2010. Regulation of stemness and stem cell niche of mesenchymal stem cells: implications in tumorigenesis and metastasis. J Cell Physiol 222(2):268-277.

Kulterer B, Friedl G, Jandrositz A, Sanchez-Cabo F, Prokesch A, Paar C, Scheideler M, Windhager R, Preisegger KH, Trajanoski Z. 2007. Gene expression profiling of human mesenchymal stem cells derived from bone marrow during expansion and osteoblast differentiation. BMC Genomics 8:70.

Kusuyama J, Seong CH, Bandow K, Kakimoto K, Ohnishi T, Matsuguchi T. 2015. I-2 Low Intensity Pulsed Ultrasound (LIPUS) Helps to Maintain the Undifferentiated Status of Mesenchymal Stem Cells. Journal of Orthopaedic Trauma 29(5):S2.

Lin W, Ezura Y, Izu Y, Aryal SA, Kawasaki M, Chantida PN, Moriyama K, Noda M. 2016. Profilin Expression Is Regulated by Bone Morphogenetic Protein (BMP) in Osteoblastic Cells. J Cell Biochem 117(3):621-628. 
Liu YS, Lee OK. 2014. In search of the pivot point of mechanotransduction: mechanosensing of stem cells. Cell Transplant 23(1):1-11.

Livak KJ, Schmittgen TD. 2001. Analysis of relative gene expression data using real-time quantitative PCR and the 2(-Delta Delta C(T)) Method. Methods 25(4):402-408.

Maxwell L, Collecutt T, Gledhill M, Sharma S, Edgar S, Gavin JB. 1994. The augmentation of leucocyte adhesion to endothelium by therapeutic ultrasound. Ultrasound Med Biol 20(4):383-390.

McBeath R, Pirone DM, Nelson CM, Bhadriraju K, Chen CS. 2004. Cell shape, cytoskeletal tension, and RhoA regulate stem cell lineage commitment. Dev Cell 6(4):483-495.

McNamara LE, McMurray RJ, Biggs MJ, Kantawong F, Oreffo RO, Dalby MJ. 2010. Nanotopographical control of stem cell differentiation. J Tissue Eng 2010:120623.

Otto F, Lübbert M, Stock M. 2003. Upstream and downstream targets of RUNX proteins. J Cell Biochem 89(1):9-18.

Papadimitropoulos A, Piccinini E, Brachat S, Braccini A, Wendt D, Barbero A, Jacobi C, Martin I. 2014. Expansion of human mesenchymal stromal cells from fresh bone marrow in a 3D scaffold-based system under direct perfusion. PLoS One 9(7):e102359.

Pittenger MF, Mackay AM, Beck SC, Jaiswal RK, Douglas R, Mosca JD, Moorman MA, Simonetti DW, Craig S, Marshak DR. 1999. Multilineage potential of adult human mesenchymal stem cells. Science 284(5411):143-147.

Pricola KL, Kuhn NZ, Haleem-Smith H, Song Y, Tuan RS. 2009. Interleukin-6 maintains bone marrow-derived mesenchymal stem cell stemness by an ERK1/2-dependent mechanism. J Cell Biochem 108(3):577-588.

Rawool NM, Goldberg BB, Forsberg F, Winder AA, Hume E. 2003. Power Doppler assessment of vascular changes during fracture treatment with low-intensity ultrasound. J Ultrasound Med 22(2):145-153.

Ringdén O, Le Blanc K. 2006. Mesenchymal stem cells combined with cyclosporine inhibits cytotoxic T cells. Biol Blood Marrow Transplant 12(6):693-694.

Rutten S, Nolte PA, Korstjens CM, Klein-Nulend J. 2009. Low-intensity pulsed ultrasound affects RUNX2 immunopositive osteogenic cells in delayed clinical fracture healing. Bone 45(5):862-869.

Saalbach A, Haustein UF, Anderegg U. 2000. A ligand of human thy-1 is localized on polymorphonuclear leukocytes and monocytes and mediates the binding to activated thy-1-positive microvascular endothelial cells and fibroblasts. J Invest Dermatol 115(5):882-888.

Salasznyk RM, Westcott AM, Klees RF, Ward DF, Xiang Z, Vandenberg S, Bennett K, Plopper GE. 2005. Comparing the protein expression profiles of human mesenchymal stem cells and human osteoblasts using gene ontologies. Stem Cells Dev 14(4):354366.

Sato M, Kuroda S, Mansjur KQ, Khaliunaa G, Nagata K, Horiuchi S, Inubushi T, Yamamura Y, Azuma M, Tanaka E. 2015. Low-intensity pulsed ultrasound rescues insufficient salivary secretion in autoimmune sialadenitis. Arthritis Res Ther 17:278.

Scadden DT. 2006. The stem-cell niche as an entity of action. Nature 441(7097):1075-1079.

Scherzed A, Hackenberg S, Froelich K, Rak K, Schendzielorz P, Gehrke T, Hagen R, Kleinsasser N. 2016. The differentiation of hMSCs counteracts their migration capability and pro-angiogenic effects in vitro. Oncol Rep 35(1):219-226.

Schofield R. 1978. The relationship between the spleen colony-forming cell and the haemopoietic stem cell. Blood Cells 4(1-2):7-25.

Stolzing A, Coleman N, Scutt A. 2006. Glucose-induced replicative senescence in mesenchymal stem cells. Rejuvenation Res 9(1):31-35. 
Uddin SM, Qin YX. 2013. Enhancement of osteogenic differentiation and proliferation in human mesenchymal stem cells by a modified low intensity ultrasound stimulation under simulated microgravity. PLoS One 8(9):e73914.

Wang Y, Peng W, Liu X, Zhu M, Sun T, Peng Q, Zeng Y, Feng B, Zhi W, Weng J, Wang J. 2014a. Study of bilineage differentiation of human-bone-marrow-derived mesenchymal stem cells in oxidized sodium alginate/ $\mathrm{N}$-succinyl chitosan hydrogels and synergistic effects of RGD modification and low-intensity pulsed ultrasound. Acta Biomater 10(6):2518-2528.

Wang Z, Cheung D, Zhou Y, Han C, Fennelly C, Criswell T, Soker S. 2014b. An in vitro culture system that supports robust expansion and maintenance of in vivo engraftment capabilities for myogenic progenitor cells from adult mice. Biores Open Access 3(3):79-87.

Yoon DS, Kim YH, Lee S, Lee KM, Park KH, Jang Y, Lee JW. 2014. Interleukin-6 induces the lineage commitment of bone marrow-derived mesenchymal multipotent cells through down-regulation of Sox 2 by osteogenic transcription factors. FASEB J 28(7):3273-3286.

Yoshimura H, Muneta T, Nimura A, Yokoyama A, Koga H, Sekiya I. 2007. Comparison of rat mesenchymal stem cells derived from bone marrow, synovium, periosteum, adipose tissue, and muscle. Cell Tissue Res 327(3):449-462.

Yoshimura K, Shigeura T, Matsumoto D, Sato T, Takaki Y, Aiba-Kojima E, Sato K, Inoue K, Nagase T, Koshima I, Gonda K. 2006. Characterization of freshly isolated and cultured cells derived from the fatty and fluid portions of liposuction aspirates. J Cell Physiol 208(1):64-76.

Yue Y, Yang X, Wei X, Chen J, Fu N, Fu Y, Ba K, Li G, Yao Y, Liang C, Zhang J, Cai X, Wang M. 2013. Osteogenic differentiation of adipose-derived stem cells prompted by low-intensity pulsed ultrasound. Cell Prolif 46(3):320-327.

Yun HM, Ahn SJ, Park KR, Kim MJ, Kim JJ, Jin GZ, Kim HW, Kim EC. 2016. Magnetic nanocomposite scaffolds combined with static magnetic field in the stimulation of osteoblastic differentiation and bone formation. Biomaterials 85:88-98.

Ziros PG, Gil AP, Georgakopoulos T, Habeos I, Kletsas D, Basdra EK, Papavassiliou AG. 2002. The bone-specific transcriptional regulator Cbfal is a target of mechanical signals in osteoblastic cells. J Biol Chem 277(26):23934-23941. 


\section{Figure Legends}

Fig. 1. LIPUS set-up experiment: (a) Top and lateral view of plexiglas transducers support; (b) Characteristic of the ultrasound signal: $200-\mu$ s burst of $1.5 \mathrm{MHz}$ sine waves repeated at 1 $\mathrm{kHz}$.

Fig. 2. (a) PCA analysis of MSCs cells grown in different condition. Regardless of exposure to LIPUS, PC1 clearly separates MSCs grown in OM from MSCs grown in MSCGM, while PC2 separates LIPUS treated cells from LIPUS untreated cells. Same color points represent single biological replicate of each growth condition. (b) Heat map presentation of a hierarchical cluster of all 557 quantified proteins in four analyzed cell grown conditions (each in duplicate).

Fig. 3. Venn diagram showing the proteins up- and down- regulated in the indicated comparisons. The numbers in brackets represent the total number of up- or down regulated proteins in the respective comparison.

Fig. 4. Protein-protein interaction network analysis of proteins down-regulated in LIPUS MSCGM vs untreated OM comparison (a), and up-regulated in Untreated MSCGM vs Untreated OM comparison (b) and in LIPUS MSCGM vs Untreated OM comparison (c). The protein-protein interaction network of the proteins listed in Supporting Information Table 1 was constructed using the STRING v10 database, and shows only high confidence functional connections (confidence score $>0.7$ ). Among proteins up-regulated in Untreated MSCGM vs Untreated OM and in LIPUS MSCGM vs Untreated OM four functional overlapping networks are identified: Ribosome constituent/Protein metabolic process (green area), Glycolysis/Gluconeogenesis (blue area), RNA metabolic process/Splicing (pink area), tubulins (yellow area).

Fig. 5. Results of cell viability (a) and dsDNA content (b) of Untreated OM ( $\square$ ), LIPUS MSCGM ( $\square$ ) and LIPUS OM ( $\square$ ) cells, expressed as percentage of Untreated MSCGM values $(100 \%)$ (Mean $\pm \mathrm{SD}, \mathrm{n}=3$ duplicates). GLM analysis with 'group' and 'experimental time point' as fixed effects showed for: Cell viability -a main effect of 'experimental time', $\mathrm{F}=12.32, p<0.0005$; dsDNA content - an interaction between 'group' and 'experimental time', $\mathrm{F}=12.42, p<0.0005$. Adjusted Sidak multiple comparison test $\left(*, p<0.05\right.$; ${ }^{* *}, p<$ $0.005 ; * * *, p<0.0005)$.

Fig. 6. Human MSCs characterization through CD73, CD90, and CD105 markers (\% positive expression) in Untreated MSCGM (a) Untreated OM (b), LIPUS MSCGM (c) and LIPUS

OM (d) at 21 days. The table (e) reports the percentage of hMSC positive gate for CD73, 
CD90, and CD105 markers, as well as NANOG, SOX2 and OCT-3/4 stem cell transcriptional factors.

Fig. 7. Mineralization progress measured by the concentration of hydroxyapatite expressed as

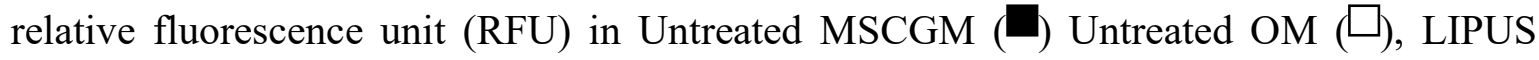
MSCGM $(\square)$ and LIPUS OM $(\square)$ cells (Mean \pm SD, n=3 duplicates). GLM analysis with 'group' and 'experimental time' as fixed effects revealed for mineralization - an interaction between 'group' and 'experimental time', $\mathrm{F}=24.11, p<0.0005$. Adjusted Sidak multiple comparison test $\left(^{*}, p<0.05 ; * *, p<0.005 ; * * *, p<0.0005\right)$.

Fig. 8. Results of RUNX2 (a), ALPL (b), COL1A1 (c), SPP1 (d) and BGLAP (e) gene expression of Untreated OM $(\square)$, LIPUS MSCGM $(\square)$ and LIPUS OM $(\square)$ cells expressed as relative fold changes (RF) of Untreated MSCGM values (1) (Mean $\pm \mathrm{SD}, \mathrm{n}=3$ duplicates). GLM analysis with 'group' and 'experimental time' as fixed effects revealed for: RUNX2 -an interaction between 'group' and 'experimental time', $\mathrm{F}=3.07, p<0.05 ; A L P L-$ main effects of 'group', $\mathrm{F}=5.09, p<0.05$ and 'experimental time' $\mathrm{F}=11.94, p<0.0005 ;$ COL1A1 - main effects of 'group', $\mathrm{F}=9.18, p<0.005$ and 'experimental time' $\mathrm{F}=4.92, p<0.05$; $S P P 1$ - main effects of 'experimental time' $\mathrm{F}=19.78, p<0.0005 ; B G L A P$ - an interaction between 'group' and 'experimental time', $\mathrm{F}=3.22, p<0.05$. Adjusted Sidak multiple comparison test $(*, p<0.05 ; * *, p<0.005 ; * * *, p<0.0005)$.

Fig. 9. Results of MAPK1 (a), MAPK6 (b) gene expression of Untreated OM ( $\square$ ), LIPUS MSCGM ( $\square$ ) and LIPUS OM $(\square)$ cells expressed as relative fold changes (RF) of Untreated MSCGM values (1) (Mean $\pm \mathrm{SD}, \mathrm{n}=3$ duplicates). GLM analysis with 'group' and 'experimental time' as fixed effects showed for: $M A P K 1$ - an interaction between 'group' and 'experimental time', $\mathrm{F}=5.92, p<0.005 ;$ MAPK6 - an interaction between 'group' and 'experimental time', $\mathrm{F}=4.37, p<0.005$.

Fig.10. ELISA results of alkaline phosphatase (ALP), alpha-1 type I collagen (COL1a1), osteopontin (OPN) and osteocalcin (OC) release of Untreated OM ( $\square$ ), LIPUS MSCGM $(\square)$ and LIPUS OM $(\square)$ cells expressed as fold increase of Untreated MSCGM values (Mean $\pm \mathrm{SD}, \mathrm{n}=3$ replicates). No significant interactions of 'group' and 'experimental time' effects were found on the release of ALP, COL1a1, OPN and OC. The 'group' effect for OPN $(\mathrm{F}=4.68, p<0.05)$ and COL1al $(\mathrm{F}=8.22, p<0.005)$ was significant. Adjusted Sidak's multiple comparison test independent of experimental time point: LIPUS OM versus Untreated OM (OPN: *, $p<0.05)$; LIPUS OM versus LIPUS MSCGM (OPN: *, $p$ $<0.05$; COL1: **, $p<0.005)$. 
Fig.S1. LIPUS-modulated proteins specifically related to osteogenic differentiation of LIPUS MSCGM and Untreated OM cultures in comparison to Untreated MSCGM one. Each area represents the fold of change (green: increase; red: decrease) in: CCT2, CALD1, and CTTN (cytoskeletal reorganization proteins that directly stimulates osteoblastic differentiation); LGALS3 (involved in osteogenesis and formation of bone nodules); PFN1, (down-regulated in osteogenic differentiation process); and SPARC (marker of osteogenic differentiation). 
Table 1. Quiagen gene primers specific for osteogenic differentiation or involved in the differentiating process. Their expression was normalized to the GAPDH housekeeping gene (tab.1B).

\begin{tabular}{|c|c|c|c|c|}
\hline Gene & Quiagen primers & Catalog number & $\begin{array}{c}\text { Annealing } \\
\text { temperature } \\
\left({ }^{\circ} \mathbf{C}\right)\end{array}$ & $\begin{array}{c}\text { PCR products } \\
\text { size }\end{array}$ \\
\hline$R U N X 2$ & $\begin{array}{c}\text { Hs_RUNX2_1_SG } \\
\text { QuantiTect Primer Assay }\end{array}$ & QT00020517 & 60 & $101 \mathrm{bp}$ \\
\hline ALPL & $\begin{array}{c}\text { Hs_ALPL_1_SG } \\
\text { QuantiTect Primer Assay }\end{array}$ & QT00012957 & 60 & $110 \mathrm{bp}$ \\
\hline COL1A1 & $\begin{array}{c}\text { Hs_COL1A1_1_SG } \\
\text { QuantiTect Primer Assay }\end{array}$ & QT00037793 & 60 & $118 \mathrm{bp}$ \\
\hline$B G L A P$ & $\begin{array}{c}\text { Hs_BGLAP_1_SG } \\
\text { QuantiTect Primer Assay }\end{array}$ & QT00232771 & 60 & $90 \mathrm{bp}$ \\
\hline SPP1 & $\begin{array}{c}\text { Hs_SPP1_1_SG } \\
\text { QuantiTect Primer Assay }\end{array}$ & QT01008798 & 60 & $115 \mathrm{bp}$ \\
\hline
\end{tabular}


Table 2. Gene primers specific for osteogenic differentiation or involved in the differentiating process. Their expression was normalized to the GAPDH housekeeping gene.

\begin{tabular}{|c|c|c|c|c|}
\hline Gene & $\begin{array}{l}\text { Forward primer } \\
\text { Sequence }\left(5^{\prime}->3^{\prime}\right)\end{array}$ & $\begin{array}{l}\text { Reverse primer } \\
\text { Sequence (5'->3') }\end{array}$ & $\begin{array}{c}\text { Annealing } \\
\text { temperatu } \\
\operatorname{re}\left({ }^{\circ} \mathrm{C}\right)\end{array}$ & $\begin{array}{l}\text { PCR } \\
\text { produc } \\
\text { ts size }\end{array}$ \\
\hline $\begin{array}{c}\text { MAPK } \\
1\end{array}$ & $\begin{array}{c}\text { GCGCTACACTAATCTCTC } \\
\text { GT }\end{array}$ & CTGAGGTGCTGTGTCTTCAA & 60 & $297 b p$ \\
\hline $\begin{array}{c}M A P K \\
6\end{array}$ & $\begin{array}{c}\text { GAATGGCAAATCTGCTC } \\
\text { AATT }\end{array}$ & ACAGTCCTCCCCACCACTCA & 60 & $80 \mathrm{bp}$ \\
\hline $\begin{array}{c}G A P D \\
H\end{array}$ & $\begin{array}{c}\text { ATGGGGAAGGTGAAGGT } \\
\text { CG }\end{array}$ & $\begin{array}{c}\text { GGGTCATTGATGGCAACAA } \\
\text { TATC }\end{array}$ & 65 & $107 \mathrm{bp}$ \\
\hline
\end{tabular}


a

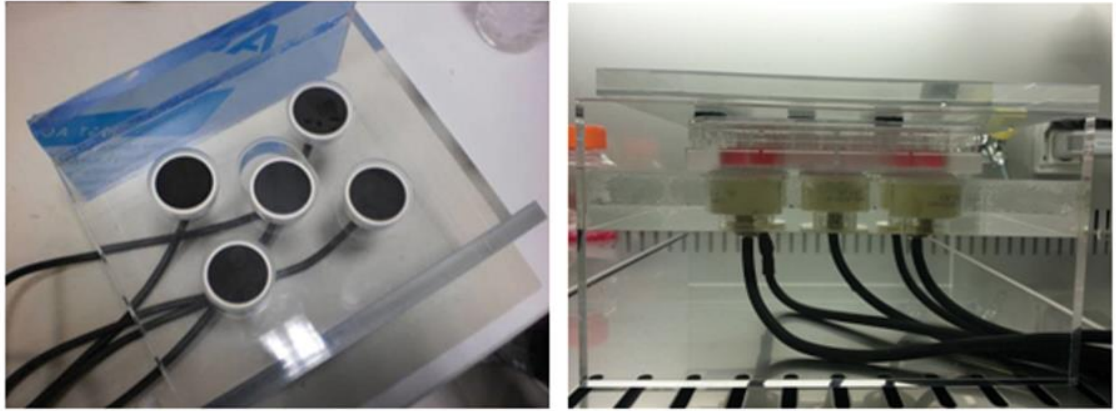

b Modulating signal burst width: $200 \mu \mathrm{s}$
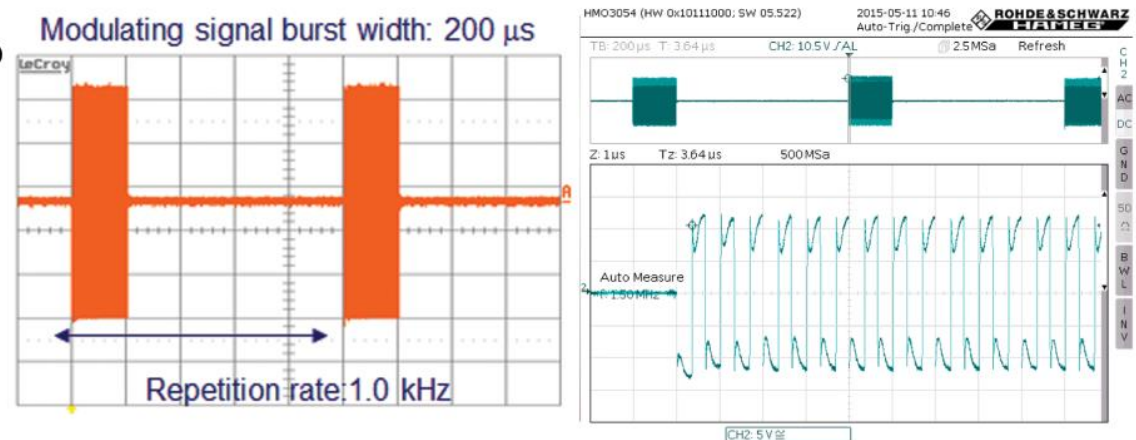

Figure 1 


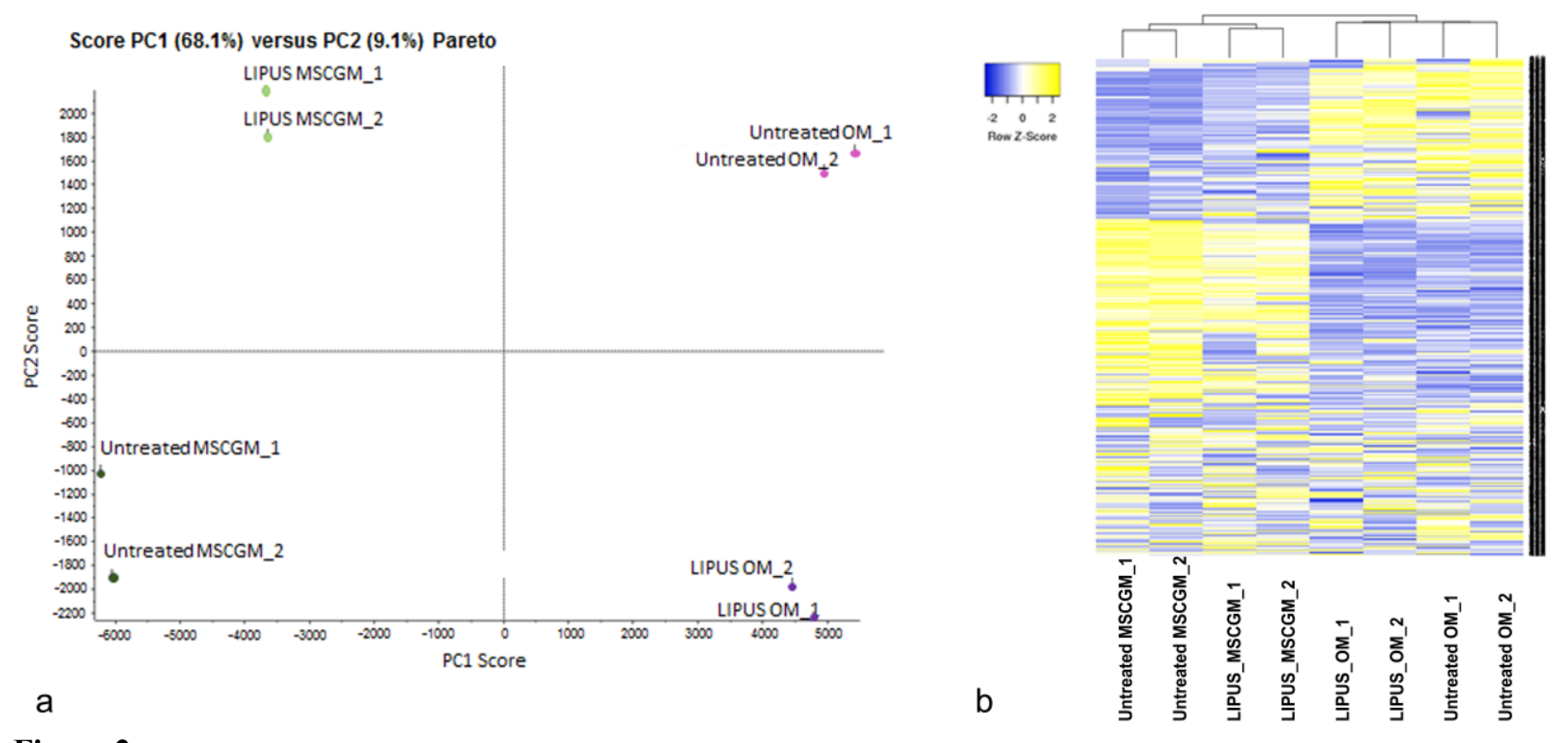

Figure 2 


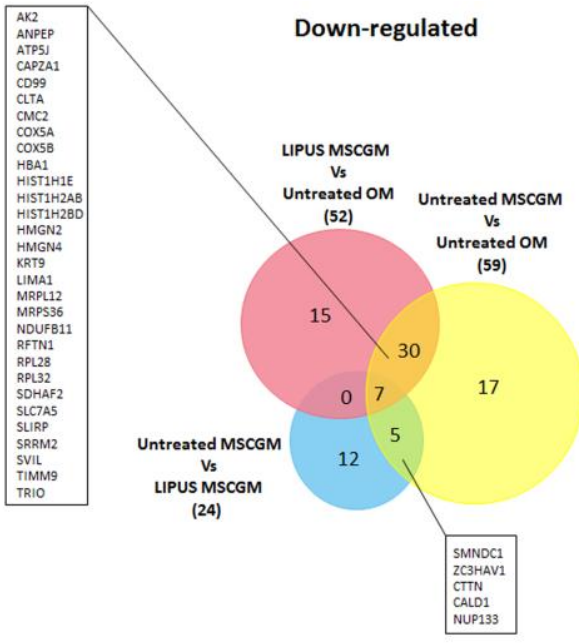

Figure 3 

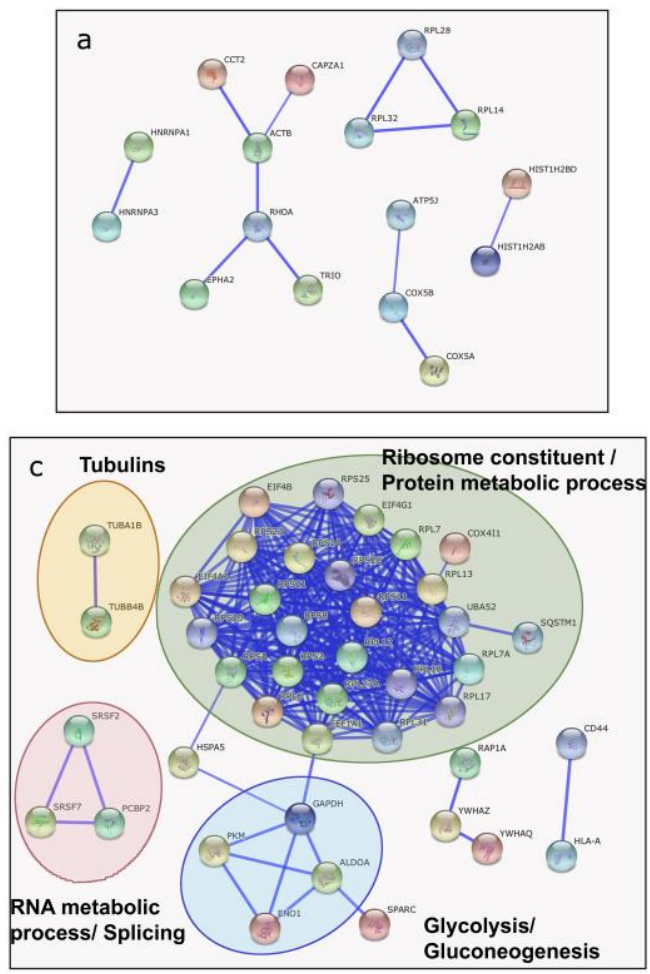

Figure 4

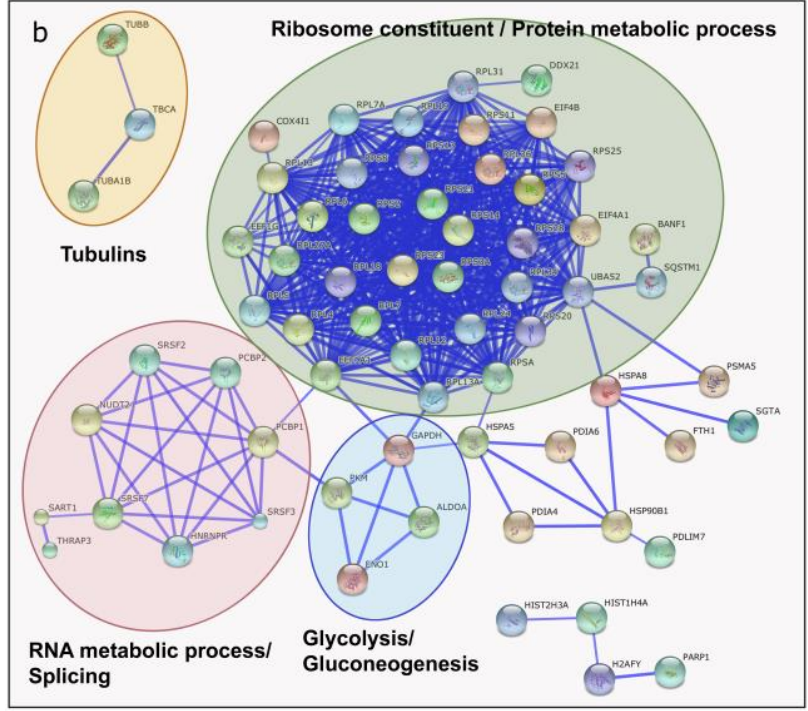

RNA meta
Splicing
Glycolysis/

(3) 

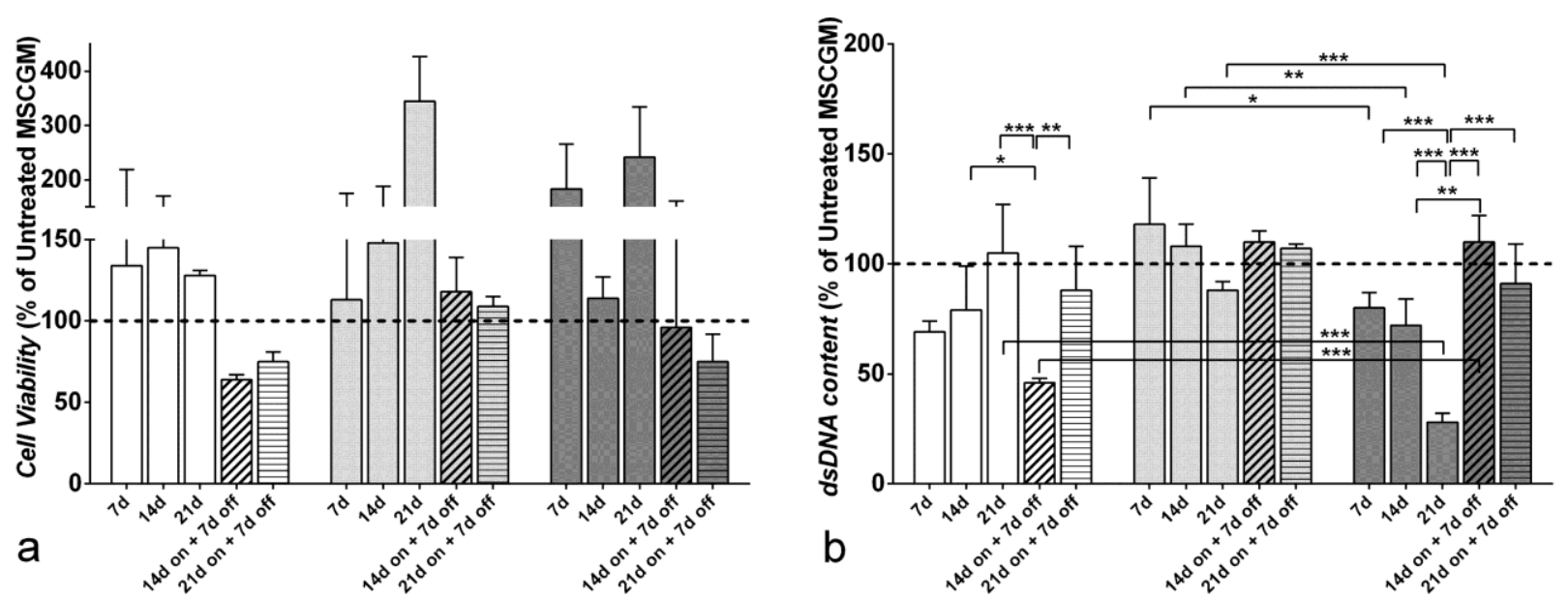

Figure 5 

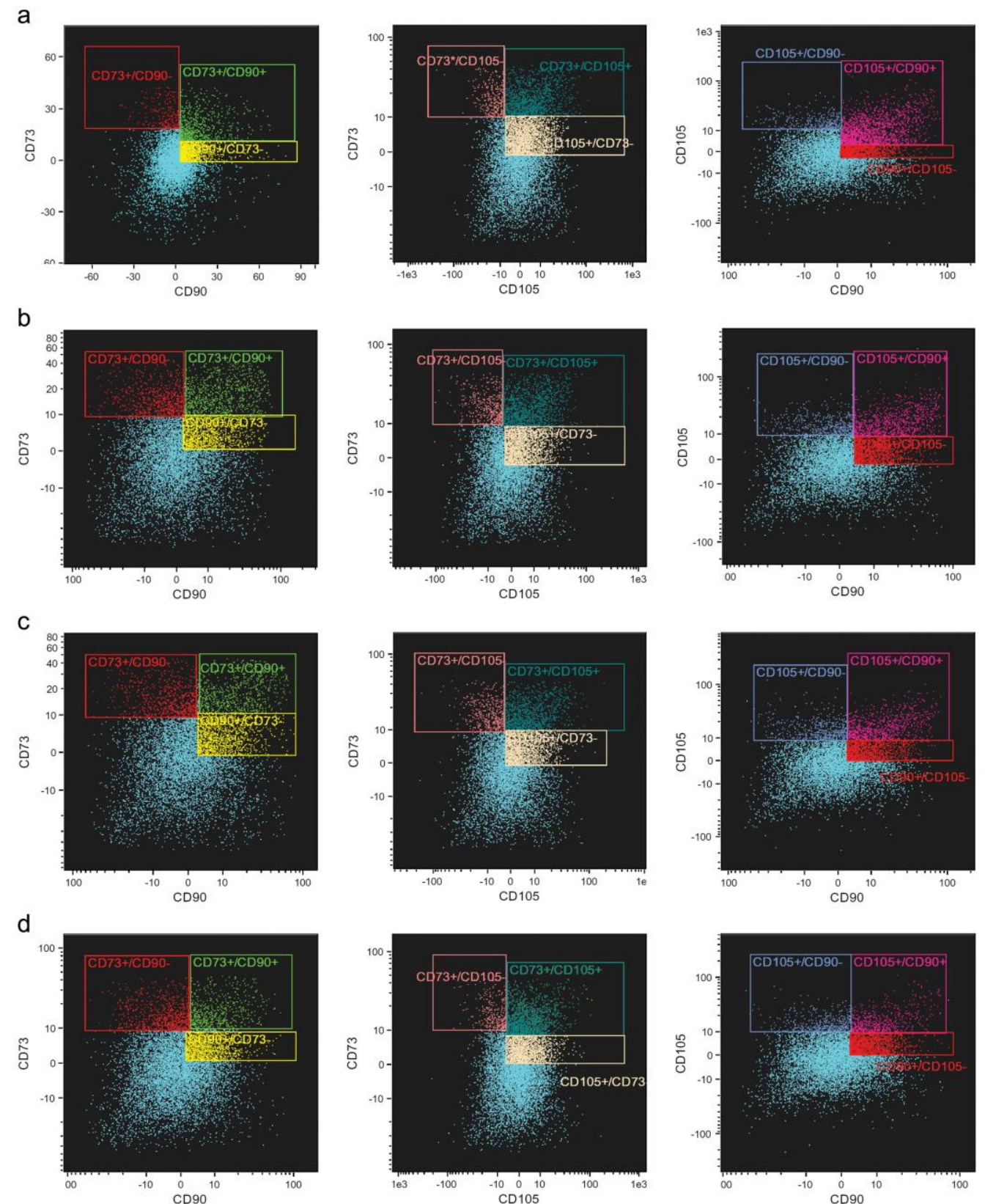

e

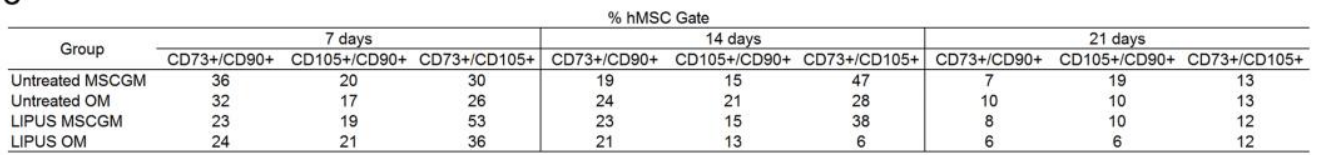

\begin{tabular}{|c|c|c|c|c|c|c|c|c|c|}
\hline \multirow[b]{2}{*}{ Group } & \multicolumn{3}{|c|}{7 days } & \multicolumn{3}{|c|}{14 days } & \multicolumn{3}{|c|}{21 days } \\
\hline & OCT4+/NANOG + & OCT $4+150 \times 2+$ & SOX2+INANOG+ & OCT4+/NANOG+ & OCT4 $4+150 \times 2+$ & SOX2+iNANOG + & OCT4+/NANOG+ & OCT4 $4+150 \times 2+$ & SOX2+/NANOG + \\
\hline Untreated MSCGM & 2 & 0.5 & 0.5 & 6 & 3 & 3 & 56 & 56 & 30 \\
\hline Untreated OM & 4 & 3 & 3.2 & 16 & 52 & 26 & 43 & 39 & 34 \\
\hline LIPUS MSCGM & 18 & 4 & 5 & 11 & 7 & 0.4 & 66 & 72 & 11 \\
\hline LIPUS OM & 17 & 7 & 8 & 70 & 65 & 65 & 38 & 10 & 10 \\
\hline
\end{tabular}

Figure 6 


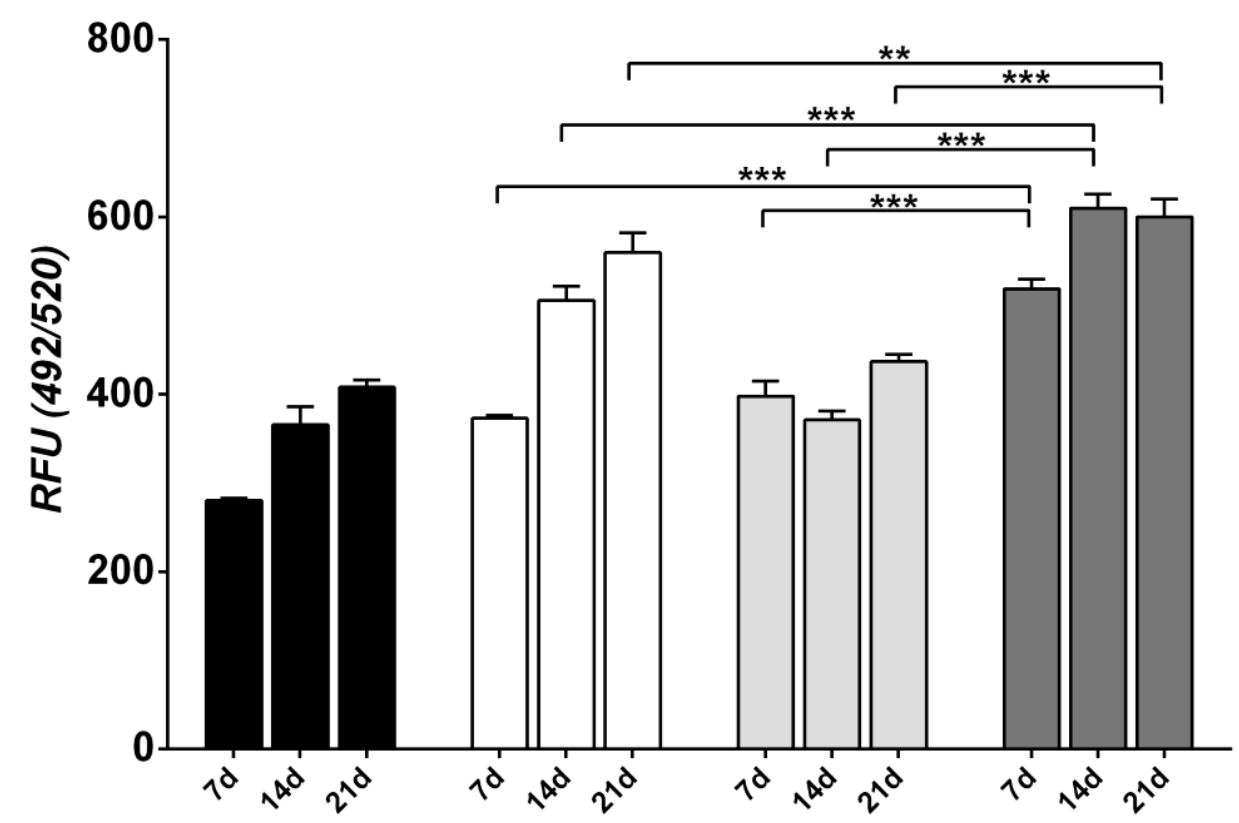

Figure 7 

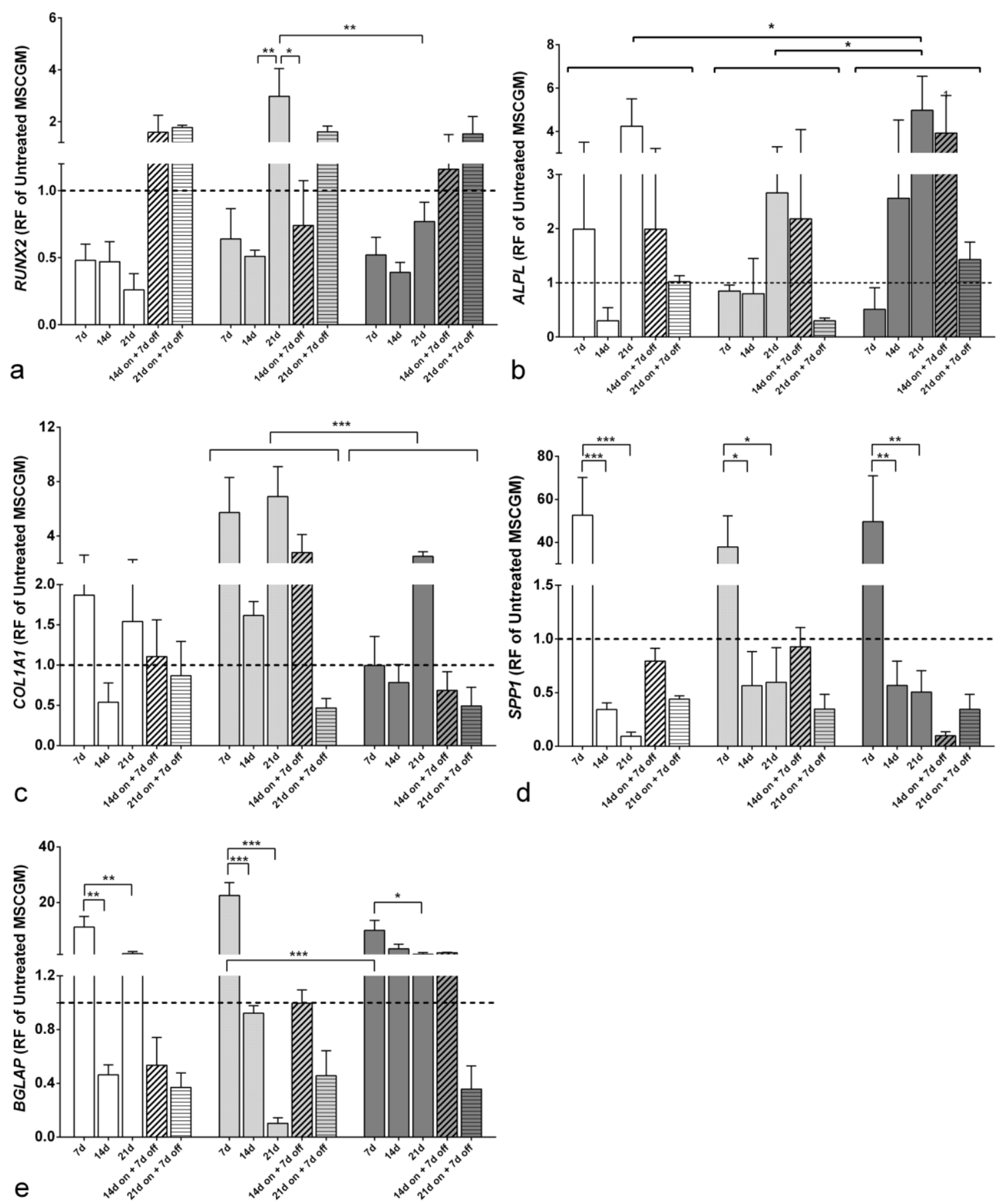

Figure 8 

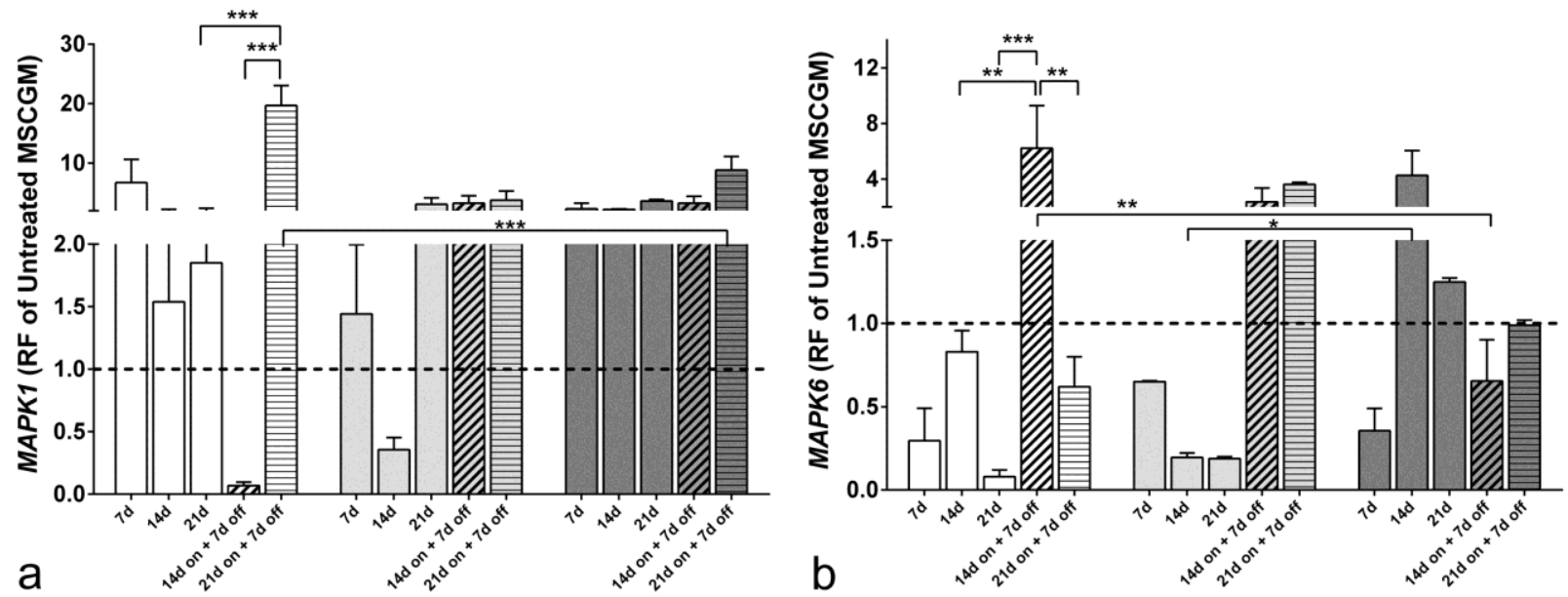

Figure 9 

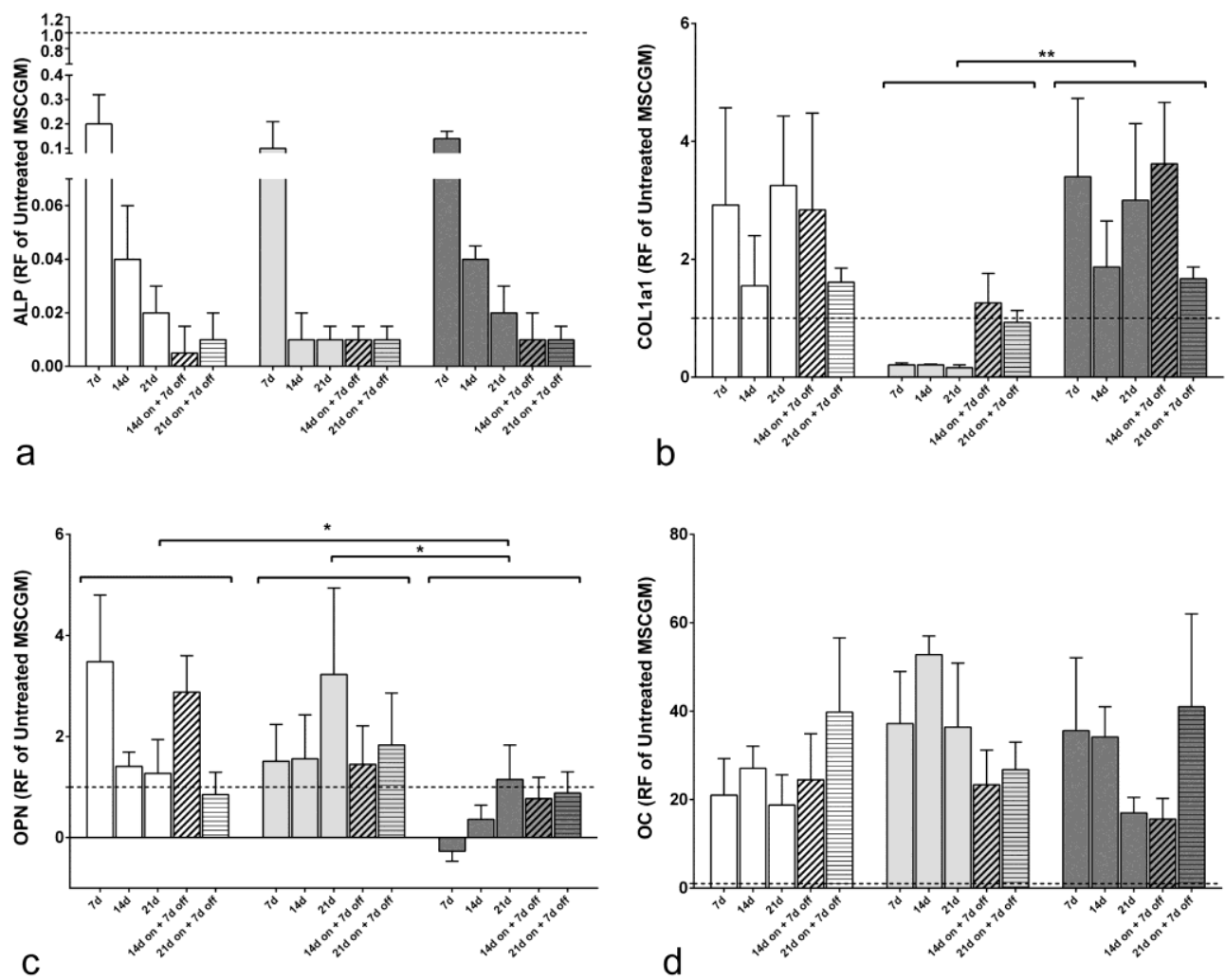

Figure 10 